\title{
Transition from higher education to the labor market: Unemployment among graduates from the gender perspective in the Palestinian Territory
}

Saleh Alkafri

Follow this and additional works at: https://knowledgecommons.popcouncil.org/departments_sbsr-pgy

Part of the Demography, Population, and Ecology Commons, Family, Life Course, and Society Commons, International Public Health Commons, Labor Economics Commons, Women's Health Commons, and the Work, Economy and Organizations Commons How does access to this work benefit you? Let us know!

\section{Recommended Citation}

Alkafri, Saleh. 2011. "Transition from higher education to the labor market: Unemployment among graduates from the gender perspective in the Palestinian Territory," Gender and Work in the MENA Region Working Paper no. 19. Cairo: Population Council. 


\section{NUMBER 19}

JUNE 2011

GENDER AND WORK IN THE MENA REGION

WORKING PAPER SERIES

Poverty, Job Quality and Labor Market Dynamics

\section{cos}

to the Labor Market:

Unemployment among Graduates

from the Gender Perspective in

the Palestinian Territory

Saleh Alkafri

12 Population Council 
Saleh Alkafri is a Director General of Economic Statistics, Palestinian Central Bureau of Statistics, Ramallah, Palestine.Email:SALEH@pcbs.gov.ps

The research presented in this publication is the result of a project funded by Canada's International Development Research Centre (www.idrc.ca).

\section{IDRC *RDI}

\section{Canadä}

\section{(f) Population Council \\ Research that makes a difference}

The Population Council confronts critical health and development issues-from stopping the spread of HIV to improving reproductive health and ensuring that young people lead full and productive lives. Through biomedical, social science and public health research in about 50 countries, the Council works with our partners to deliver solutions that lead to more effective policies, programs, and technologies to improve lives worldwide. Established in 1952 and headquartered in New York, the Council is a nongovernmental, nonprofit organization with an international board of trustees.

Population Council

Egypt Office

59 Misr Helwan Agricultural Road, Maadi, Cairo, Egypt

Tel.: (+202) 2525-5965, (+202) 2525-5967, (+202) 2525-5968

Facsimile: (+202) 2525-5962

Website: http://www.popcouncil.org

Email: pcouncil@popcouncil.org

(C) 2011 The Population Council, Inc.

Any part of this publication may be reproduced without permission for limited distribution, provided it is distributed without charge and the Population Council is acknowledged as its source. The Population Council would appreciate receiving a copy of any materials in which the text is used.

ISSN: 11879/2011 
NUMBER 19

JUNE 2011

GENDER AND WORK IN THE MENA REGION WORKING PAPER SERIES

Poverty, Job Quality and Labor Market Dynamics

\section{Transition from Higher Education} to the Labor Market:

Unemployment among Graduates

from the Gender Perspective in

the Palestinian Territory

Saleh Alkafri

(2) Population Council 



\section{Table of contents}

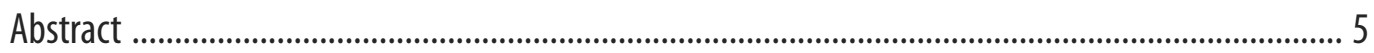

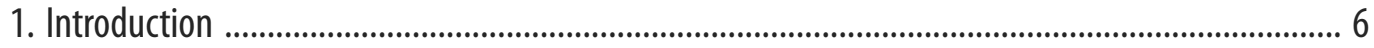

2. Review of the literature, theoretical frameworks, and previous studies .................................. 8

3. Statistical Review of the Palestinian Labor Market .................................................................... 12

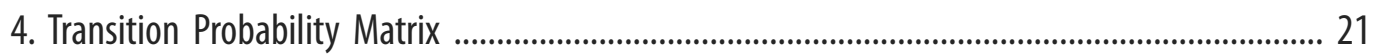

4.1 Results of Transition Probability Matrix (TPM) Analysis....................................................... 23

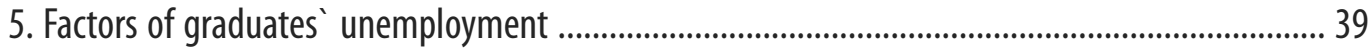

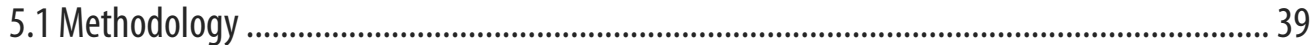

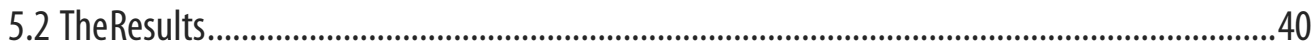

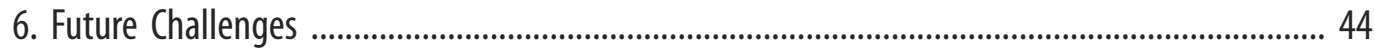

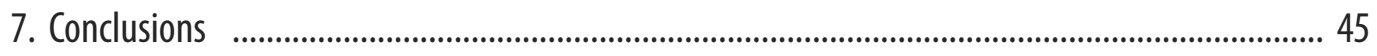

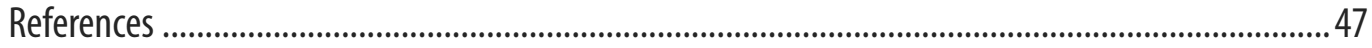

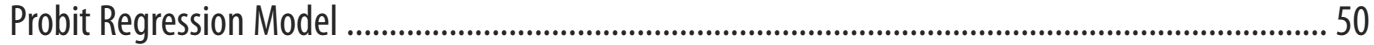

Annex 1: For persons 20-34 years old who are not attending school: West Bank 2007-2008

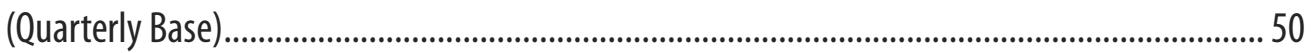

Annex 2: For persons 20-34 years old who are not attending school: Gaza Strip 2007-2008 (Quarterly Base) 

Theories and studies indicate that education is an essential factor in reducing the probability and unemployment duration and increases chances for business continuity and stability in a decent job. Nonetheless, the opposite happens to many women in the countries of the Middle East and North Africa, specifically in the Palestinian Territories, where the participation of women in the labor market is very low and high rates of unemployment are witnessed. Results indicate that the more the years of education among women the higher the unemployment rate, unlike men, causing a significant employment gap between both sexes. Then comes the question repeated in all seminars, workshops, and conferences: Why do women face low possibilities of getting a job when they decide to enter the labor market, especially those who are young and highly educated? This is the basic problem that this research study tries to tackle through highlighting and identifying the factors affecting the low potential of female graduates entering the labor market, unlike male graduates, despite their achievements in education. We have used recent data from the results of the Labor Force Quarterly Survey 1996-2008 (total Quarterly sample size for each year is 7600 households), using high technology in the methodology for rotating the sample, which provides a meticulous study of the situation. A survey of graduates in the labor market in 2006 was also used, which, in turn, provides a rich base of indicators that support the search results. It should be noted that the methodology was two-fold, including both a descriptive analysis of the available data, and a transition probability matrix and analysis of a probit regression model. The results confirmed the existence of the problem, and related the reasons for the limitations that restrict the movement of women in order to get jobs. Moreover, it shows that the problem of unemployment among graduates is worse in specific areas and disciplines that do not match the requirements of the labor market, as well as the employers' point of view of occupations and activities that women can engage in. Delays in obtaining work often lead women out of the labor market, which, in turn, causes their low participation in the workforce. The general trend toward the future puts in front of the Palestinian decision-maker extraordinary challenges to provide opportunities for jobs that take into account the geographical distribution and the programming of scientific disciplines offered by universities 


\section{Introduction}

The complex relationship between gender and work, and hence poverty, acquires widespread attention in social and developmental policies and programs. The limited possibilities for women's access to material resources or control, whether these are wealth, education, jobs, skills, or health services, make women more vulnerable to poverty. Under the difficult situations in the Palestinian Territories, there is a continuous rise in the unemployment rate. Therefore, this issue is getting increasing attention from those in power and decision-makers in the Palestinian Territories because of its negative impact on poverty, low living standards, and well-being. Recently, unemployment rates in the Palestinian Territories exceeded the expected rates compared with previous years, neighboring countries, or the least developed countries (LDC). The main cause of this deterioration is Israeli action aiming to starve the Palestinian people by all means, such as the siege imposed on most of the areas, the difficulty of traveling between cities in the Palestinian communities, the imposition of curfews on some communities for long periods, and the prevention of Palestinian workers from working in the labor market of Israel. On the other hand, there are other internal factors related to employment policies, education and other factors relevant to decision makers and incumbents.

Since the early nineties, the Palestinian economy has faced a significant shift due to several economic crises. The impacts of these crises have been declining living standards, widespread unemployment, and a widened cycle of poverty, especially among marginalized groups. These economic crises caused by the last Gulf War crisis and the Israeli actions against the Palestinian people during the first Intifada, which went on until the beginning of the second quarter of the nineties, or, after the signing of the Israeli-Palestinian agreement in September 1993 in Oslo. After 1993, aspects of growth and economic recovery began to emerge, especially after the flow of international aid to the Palestinian Territories, and the start of intensive employment in the public sector. These efforts and international assistance affected the Palestinian economy positively, but once again the economy faced a crisis by the beginning of the second quarter of 1996 , due to closures and strict action by the Israeli occupation of the Palestinian Territories (this crisis was later on named Al Aqsa-Intifada). As a result, the unemployment rate rose sharply, especially in the Gaza Strip, bringing it to $24 \%$ in the whole of the Palestinian Territory, $20 \%$ in the West Bank, and $33 \%$ in the Gaza Strip (one third of the potential workforce). After that, in the third quarter of 2000 - during the Al Aqsa - Intifada II - the 
Palestinian economic situation started to recover where the economic indicators showed gradual stabilization and the unemployment rate gradually declined, reaching its lowest level, if compared to the nineties, when the average unemployment rate reached 10\% in the whole of the Palestinian Territories; $8 \%$ in West Bank, and I6\% in the Gaza Strip. Later on, the political situation in the Palestinian Territories overturned again and the treaties between the Palestinians and the Israelis were suspended, negatively affecting all aspects of life. This situation further intensified with the Israeli aggression against the Gaza Strip at the end of 2007.

In parallel with the problem of unemployment, other challenges have emerged, such as a high rate of unemployment among female graduates compared with other groups of young women, unlike the case among young men. In other words, it is more difficult for young graduate women to get jobs than for women who did not receive an education above high school. It has been noticed clearly that the more the years of schooling for young women the higher unemployment rates, while the case is just the opposite among young males. This phenomenon has noticeably increased over time, especially whenever the number of graduates is high. The phenomenon seems contrary to what is known and what is customary in relevant theories. The prevailing view about education and unemployment shows that a high level of education protects people from unemployment (Lauer, 2005). Thus, the unemployment rate among male Palestinian graduates drops the more their years of education, while this rate rises significantly among female Palestinian graduates, the more their years of education.

If this situation persists, it may have a negative impact on the tendency of parents to educate their daughters. One example was the tendency of Palestinian families, during the period prior to the Al - Aqsa Intifada (2000), to have a pessimistic idea regarding the usefulness of education when compared with the non-educated class who worked in Israel and the settlements and earned higher salaries than individuals with higher education who were working in the local market at that time. This situation had a negative impact on school dropout rates among young people. Later on, those workers, in Israel and the settlements, lost their jobs in 2000 due to Israeli procedures causing higher rates of unemployment, especially among those with a lower level of education (Saleh, 2003).

The basic problem this study is trying to tackle and discuss is the phenomenon of unemployment and its rising rate among graduate women, when compared with graduate men. Efforts to increase women's participation in the labor market breaks down when faced with obstacles to provide employment opportunities for women. The higher the level 
of education among women, the higher their participation in the labor market, causing, in turn, higher unemployment rates. However, literature that shows the contrary was found in Daoud_(2005), where the author claims that the revenue of education for women were marginally higher than that of men. This leads to the assumption that the answer to the question held in this research is not focused on gender mainly but on how large the gap is between the different disciplines of graduates and the labor market needs. It is well known that the majority of women specialize in the humanities, while men are distributed in various disciplines.

The second problem in this research is the long period of unemployment among graduate women of higher education when compared to their counterparts. The behavior and experiences of women and men are supposed to be similar, while their attitudes differ in terms of planning for the future.

Toidentify the determinants of the phenomenon of rising unemployment among young graduate women, we will try through this paper to review the relevant available literature, previous studies, and theoretical framework in Section II. While Section III shows the reality of the Palestinian labor market and the most important changes that have taken place by using data from the Labor Force (workforce) Survey which has been implemented by the Palestinian Central Bureau of Statistics (PCBS) since 1995, as well as a descriptive analysis of some of the most important results of the survey of graduates' conditions in the labor market, which was implemented in 2006 by the PCBS. The methodology and source data used in the analysis of a transition probability matrix of participants in the workforce, a probit regression analysis and analysis of the results will appear in Section IV and V, respectively. Section VI highlights the challenges facing decision makers in the future through the development of future projections for the percentage of women with higher education and their participation in the workforce, i.e., the future bulk of women's participation in the labor market by using simple possible scenarios, away from the political solutions that affect the labor market. Finally, section VII will address the most important conclusions of this study.

\section{Review of the literature, theoretical frameworks, and previous studies}

The basic premise of the search for a theoretical framework is an incomplete knowledge of women and men in the labor market. Youth and staff with low and little relevant experience have limited information 
on facilities, wages, working conditions, employment policies, and other important job specifications together with the skills and abilities possessed by the job seeker. Consequently, they face high costs to obtain information, and, in turn, employers have limited information about job seekers. Original and basic contributions of the theory of job searching had been concentrated in the analysis of the period of unemployment, since the period of looking for work, in terms of scarcity of jobs, could adversely affect the success in the labor market. There are at least two reasons for the direct impact of a period of unemployment that can also affect the individual's opportunity to get a job. First, looking for work can drop with the length of the period of unemployment. Secondly, the length of unemployment of an individual has a negative impact on achievement and performance in the labor market. But other studies exclude the impact of the length of the unemployment on the performance in the labor market in terms of whether this job unemployment comes within a general framework and a rise in unemployment in that framework or specialization (Lauer, 2005).

Many studies have examined the period of transition from school to the labor market, where some specified the relationship between the period between school exit and getting the first job and the acceptable wages for that job using the conceptual model for labor market requirements and job seeker availability. In (Ryan, 200I), the author concluded that the acceptable wage decreases as the period of unemployment gets longer. Also, they described the distinction between unemployment and lack of participation in the labor market as "fuzzy," especially in the presence of the many difficulties in finding employment opportunities faced by youth, who could become economically inactive rather than jobseekers. This applies to Palestinians living in the Palestinian Territories, who face high unemployment rates, especially young women graduates. This, in turn, makes their rate of labor force participation lower while increasing reluctance among them to participate in the labor market under the difficult conditions for obtaining jobs.

The main criticisms regarding the movement of graduates from school to the labor market can be identified as inadequate educational achievements, the scarcity of jobs, higher recycling of jobs, and the weak linkages between education output and labor market requirements. The unemployment rate indicator is acceptable to explain the problems of youth employment (Ryan, 200I), thus the scarcity of jobs for graduates living in the Palestinian Territories is classified as their main problem. Nonetheless, the high unemployment rate is the best proof of the magnitude of the problem faced by graduates in the Palestinian Territories and the region. 
But education does not just classify individuals according to their skills and abilities, or just affect knowledge held by job seekers about how they can find a job. Studies also show that high levels of education affect the length of the search for work. Analyses revealed that the length of time spent searching for work between the period of study and work is less for individuals who have higher educational degrees (Kettunen, 1997). The relationship between education and unemployment has been discussed extensively. In addition, the relationship between education, job rotation, and the transition between jobs is very important in understanding the youth labor market. Some studies have shown that a high level of education raises the probability of staying in a job, and reduces the possibility of facing unemployment. Mahwele has confirmed that higher levels of education accompanied an increased likelihood of employment (Mahlwele, 2009). The study showed that women in South Africa who have a higher level of education have better opportunities to work than contrary to the uneducated ones.

Confirming the previously mentioned issues, a recent local research study was published about "Reality of graduates seeking employment: What do Palestinian women need from the labor market and how to get it" by the Palestinian Women's Research and Documentation Center PWRDCUNESCO with results that a large part of the causes of unemployment in the community of Palestinian women is a weak economy and lack of jobs, as well as the large number of graduates in similar fields and the competition among graduates of females within certain professions such as education. Moreover, a large number of women are willing to return to the labor market if they were given the chance and they are ready to consider alternatives, such as a change in specialization and seeking a job outside the geographical scope of the residential area. The study concluded that unemployment is often imposed on women, not being purely by choice.

Through auditing, research, and reviewing the output of the abovementioned study, in particular the qualitative analysis of the causes of unemployment as defined by the women who participated in the focus groups, researchers reported that the lack of offered jobs resulted in strong competition between graduates for these jobs, especially in specific disciplines, were some of the most important reasons for not being able to get a job. Therefore, both young men and women encounter the same problems in finding a job. Furthermore, graduates reported that discrimination against women has had a role in their lack of job opportunities. The results show that more than $90 \%$ of those asked indicated that the scarcity of jobs and graduate congestion form a major cause of unemployment, compared with $29 \%$ who attributed the problem 
to discrimination ${ }^{\mathrm{I}}$. Meanwhile the indicators of the labor force survey show that there is a clear gap in the level of unemployment among males and females. A group of graduate women said that "The rate of high graduates has increased and graduates compete to posts. Tulkarem has the highest rate of higher education in the West Bank. In every family there are four or five graduates, mostly unemployed. With respect to discrimination between male and female, a woman in the focus groups stated that an executive in one of the companies described young males in the labor market by saying that a man can manage and control time being not restricted to return home at specific times. Moreover, he would not seek leave for birth and breast - feeding and sit at home in the event of a child`s illness." Participants also said that the requisite of past experience by most institutions is another reason for unemployment, especially amongst fresh graduates, who were not given that privilege yet.

Another recent study by the Palestinian Women Research and Documentation Center PWRDC - UNESCO on the work of Palestinian women titled, the "Study on the Impression of Palestinians and their Attitudes towards Women's Work," showed that one of the main obstacles facing women is night work, which is not acceptable for women-such as the work until late hours of a day in software and telecommunication companies. Because of the fear of sexual harassment in the workplace it is unacceptable for women to work outside of the home at night. These factors can limit the options of work for graduates, in addition to the fact that the majority of them seek a job with social security benefits.

Furthermore, according to the results of the study mentioned earlier, higher unemployment rates - which generate a prolonged period of unemployment - have negative effects on the unemployed. It has been described by one of the graduates that the worst thing in this situation is the time wasted without doing something. It reduces their ambition and slows down their ability to continue looking for a job, and, eventually, it leads to despair in not finding a job, taking them out of the labor market. All of this will surely cause a decline in the participation rate of women in the workforce.

On the other hand, a report on women and work issued by the Palestinian Women Research and Documentation Center - UNESCO points out that discrimination against women by the labor market or the family - through the restrictions imposed on their daughters - is a key role in the inability of graduate women to get a job. Moreover, the field of study is usually imposed on young girls by their families. Consequently, after graduation they cannot work in a proper place or outside their immediate residential

1 The graduates could select more than one reason. 
area and therefore cannot apply for all available jobs, since most of are based in the centre of the West Bank i.e., Ramallah. Needless to say, most women, $69 \%$, prefer to work in the public sector. The report noted that $80 \%$ of single women and $95 \%$ of married women do not accept work in other cities that would take them away from their families. Of course, such restrictions limit their search from all available opportunities to only those that seem acceptable to their families and society. It is also noted that the fields study that women choose, or are imposed on them, impact their attainment of employment, because many girls do not choose fields of study appropriate to the needs of the labor market.

\section{Statistical Review of the Palestinian Labor Market}

This section highlights the reality of the labor market in the Palestinian Territories and the structural changes that have occurred over the past few years to show the environment surrounding graduates. It also deals with the circumstances of graduates, their behavior in the search for work, methodology, and the obstacles they face. Through statistical presentation, we can determine the map of reality that surrounds the graduates, in order to facilitate reading the results of in - depth analysis of some factors and constraints that determine the low employment opportunities for graduates. It is worth noting here, that in some parts we will introduce statistical reading and analysis for the West Bank and the Gaza Strip separately due to several differences in political and economic factors surrounding the labor market in order to understand the constraints in isolation from other influences. The Gaza Strip is completely closed off and suffers from a severe economic crisis that affects all segments of society, compared to a relatively better situation in the West Bank.

It is well-known that unemployment occurs when a surplus of manpower exceeds the needs of the labor market. As a prelude to this, we find that the available female participation in the labor force in the Palestinian Territory is very low, to the extent that it is considered one of the lowest worldwide. The annual rate of female participation in the labor force in the Palestinian Territory did not exceed $16 \%$, while the rate of male participation exceeded $70 \%$. This difference is widely witnessed when considering the West Bank and the Gaza Strip, particularly in the Gaza Strip, where the participation of women in the workforce did not exceed $11.7 \%$ in 2008, while in the West Bank the rate was $17.1 \%$. However, the supply of highly educated females in the labor force is relatively high, when compared with other groups, and this is one of the reasons behind the high rate of unemployment among graduate women. 
The general age structure of the levels of participation rates among men and women in the labor force is identical, but the difference is in the level. Middle aged men and women are active in the labor market, but the dynamism of men remains much higher than that of women. This is because of several social, economic, and cultural reasons (see Figure I). Details of this issue in the Palestinian Territories can be found in a study (Daoud, I999) which tries to identify the constraints of women's participation in the labor market. It was also noted that education plays a fundamental role in raising women's participation in the labor market. The participation rate rises from almost $10 \%$ for women (aged 15 years and over) who did not complete more than I2 years of schooling to more than $40 \%$ of those who have completed more than I2 years of schooling (see Figure 2).

Figure 1: Percentage of participation by age and gender 2008

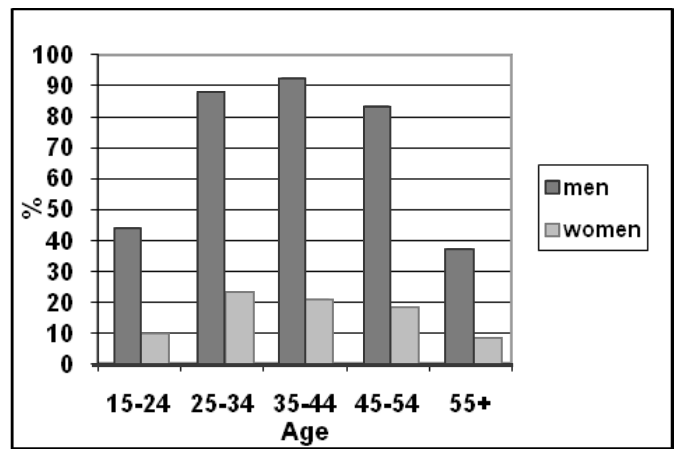

Figure 2: Percentage of participation by years of education and gender 2008

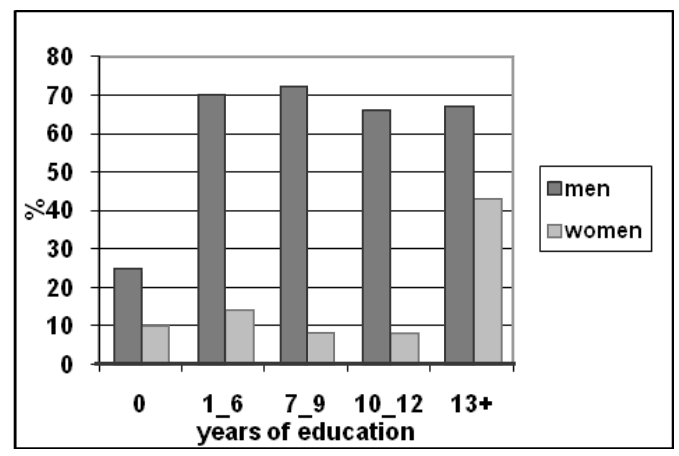

Source: Palestinian Central Bureau of Statistics (PCBS), 2009, database of workforce survey 1996-2008, Ramallah, Palestine.

To generate a more accurate comparison of the labor force participation rates of women and men, taking into account levels of education, we will take the youth group $\left(20^{-} 34\right.$ years old) that recently came out of the educational system, and compare between the data of years 1999 and 2008 in order to show change over the past Io years. It should be noted that I999 was one of the most stable years since the Oslo agreement in 1993.

One of the fundamental changes that occurred during the period 1999 to 2008 was the rise in the higher education rate among women aged 2034 if compared to that of men. As a result, the number of women graduates became greater than the number of their male counterparts, whereas the situation was reversed in 1999. The number of women graduates during that period, increased by $94 \%$ to 78,800 , while the increase of this ratio among men was only by $46 \%$ to 71.700 . On the other hand, the number of men who graduated from community colleges decreased, since 
most of them preferred a B.A. or other higher degrees. It is also clear that community colleges provided a shorter and less expensive learning environment for young women, which led to an increase in the number of diploma graduates among women. It was also noted that the acceleration in women in education compared with men in the West Bank is higher than that in the Gaza Strip, where levels remain generally higher in the Gaza Strip than in the West Bank.

Witnessing a growing number of graduates, as well as an acceleration in graduate rates and graduates with a B.A. degree or higher, it is noted that the participation rate of female graduate in the labor market is increasing more than the percentage growth in education. As a result, the level of the supply of an educated workforce in the labor market is rising, especially among women. While the percentage of graduate and economically active women is $37 \%$ of the total graduates (economically active men and women aged ${ }^{2} \mathrm{O}^{-34}$ ) in 1999 , the proportion rose to nearly half $(48 \%)$ in the year 2008. The indicators show an increase in graduate and economically active women that reached $\mathrm{II}_{3} \%$, increasing the participation rate of women from $68 \%$ in 1999 to $75 \%$ in 2008 , compared to a low participation rate increase among young graduate men from $95 \%$ to $90 \%$ during the same period.

Figure 3: Unemployment rate among women by number of years of education (1999-2008)

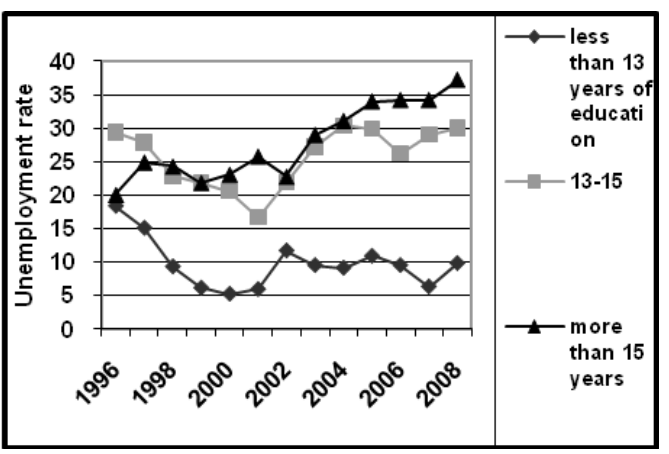

Figure 4: Unemployment rate among men by number of years of education (1999-2008)

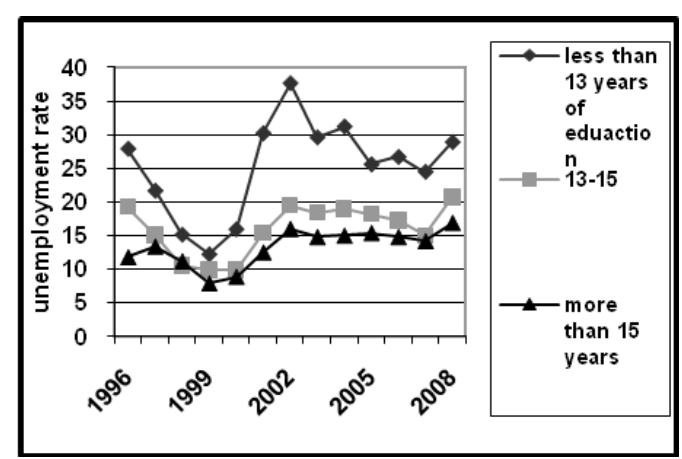

Source: Palestinian Central Bureau of Statistics (PCBS), 2009, database of workforce survey 1996-2008, Ramallah, Palestine.

A rise in the levels of education and of the participation of women in the workforce was accompanied by a decrease in the demand for that category. Rates of unemployment among women increased significantly compared with the same group of young men. Rates of unemployment among graduate men are much less than among graduate women, compared with that of non-graduates. However, a convergence in the rate 
of unemployment among graduate and non-graduate men is noted, whereas these rates differ significantly from women, where the unemployment rate among graduate women is four times higher than that of non-graduates (who left the pre-degree diploma). This situation remained constant before and after Al-Aqsa Intifada in 2000 , except for the bulk of unemployment, where unemployment rates rose dramatically after the al-Aqsa Intifada. It should be noted that this gap is much higher in the Gaza Strip than in the West Bank. In general, this is an indicator that the gap between unemployment of graduate and non-graduate women is not the result of recent events in the Palestinian Territories but that it is an ongoing phenomenon. Therefore, this gap is not affected by the economic crises experienced by the Palestinian Territories since the Al-Aqsa Intifada (see Figures 3 and 4 ).

The emergence of the dependency factor is one of the most important variables in measuring the extent to which women search for jobs. The higher the dependency ratios per worker of the family, the more persistently the women search for jobs, an indication that the culture of women's work stems from economic necessity. Based on survey data on the working conditions of graduates $(2006)^{2}$, the results show that female graduate who persistently look for jobs belong to families with a dependency ratio of 5.3 persons per worker, compared to a ratio of 4.6 per worker for females outside the labor force.

On the other hand, the results of the survey of the status of graduates in 2006 show that the period of unemployment of graduates has decreased since the Palestinian National Authority became in charge of the Palestinian Territories in 1993. The period of unemployment for women was higher than for men before the Oslo Agreement, then it started to decline gradually for both genders, but more rapidly for women, finally the period has become shorter for women than for men until 2005 . This index could be a positive indicator for the improvement of the performance of women in the labor market. But sometimes, the decline in the unemployment period is a negative indicator, because sometimes in difficult circumstances and after long periods of waiting or searching for jobs, people are lead out of the labor force and they stop searching for jobs instead of getting a one. This group has been termed "desperate job seekers," and it applies more often to women (see Figure 5).

2 The survey conducted by the Palestinian Central Bureau of Statistics PCBS, Ramallah, Palestine. 
Figure 5: The average duration of unemployment (in months) for those who looked for work since the graduation, and their relationship with the current labor force by sex

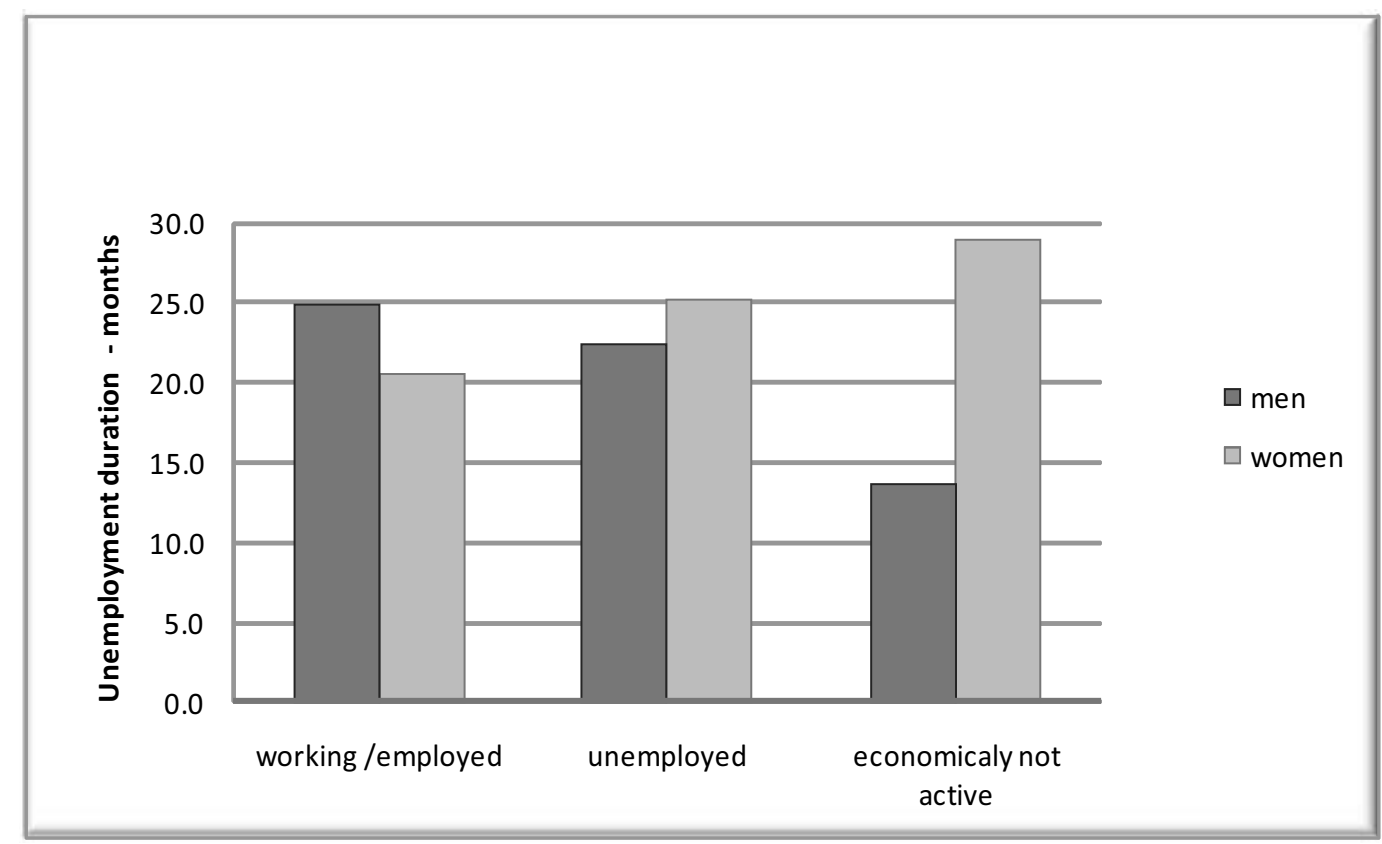

Source: The Palestinian Central Bureau of Statistics PCBS, 2006. Database of the survey of the conditions of graduates 2006, Ramallah, Palestine.

The above mentioned survey also shows the average period of unemployment for both men and women who looked for work after graduation. It was found that the duration of unemployment for graduates who got a job was the longest, followed by the graduates who continued to look for work (unemployed), and the duration declined for inactive male graduates, while the exact opposite was true for female graduates. This shows that the long period of unemployment possibly correlated with higher rates of unemployment, thus continuing delays in obtaining a job gives better opportunities to recent graduates. But here the question poses itself about why does it take graduate women a longer time to get a job? It has been noticed that when a women remains unemployed for a long period, she stops searching for a job and leaves the labor force, resulting in lower participation rates of women in the workforce compared with men. It is clear that the average period of unemployment, which forces a women out of the labor market is 29 months. Regarding this long period of unemployment, an important question rises as to whether there are any job specifications that women are looking for that differs from those that young men are looking for. The results of the survey of conditions of graduates in 2006 showed that there are some differences between the job descriptions that men and women seek. The dominant characteristic is that the post would commensurate with 
their qualifications, which is a right of graduates, with a total percentage to $62 \%$ and $53 \%$ for both men and women respectively. It was observed that women want to work in an environment suitable for privacy which cannot be established in the labor market, especially in areas distant from the central region. This condition, found in $16 \%$ of women, restricts them from finding what they hope. Of female graduates, only ro\% were interested in getting jobs as teachers, knowing that the public schools employ a limited number of graduates each year that does not meet the number of graduates. Young men can work in both girls and boys schools, while women prefer to work only in girls schools, which increases competition. On the other hand, private schools are concentrated mostly in the central region; graduate women who reside out of the central region find that it is not feasible to work in centrally located private schools. Another interest for both genders is the willingness to get jobs in the public sector, accounting for up to $8 \%$ and $7 \%$ for men and women, respectively. As for men, there is a high percentage, of up to $15 \%$, who accept any work and only $5 \%$ of women. Moreover, 10\% of men want to earn a high income. In addition to these requirements, other special requisites for women and their inflexible movement to job locations limit their gaining access to jobs that commensurate with their interests. It is therefore possible that this has a direct impact on the high rates of unemployment among graduate women (see Figure 6).

Figure 6: Percentage distribution of unemployed and inactive graduates ( $20-34$ years old) by gender and the desired work type (2006).

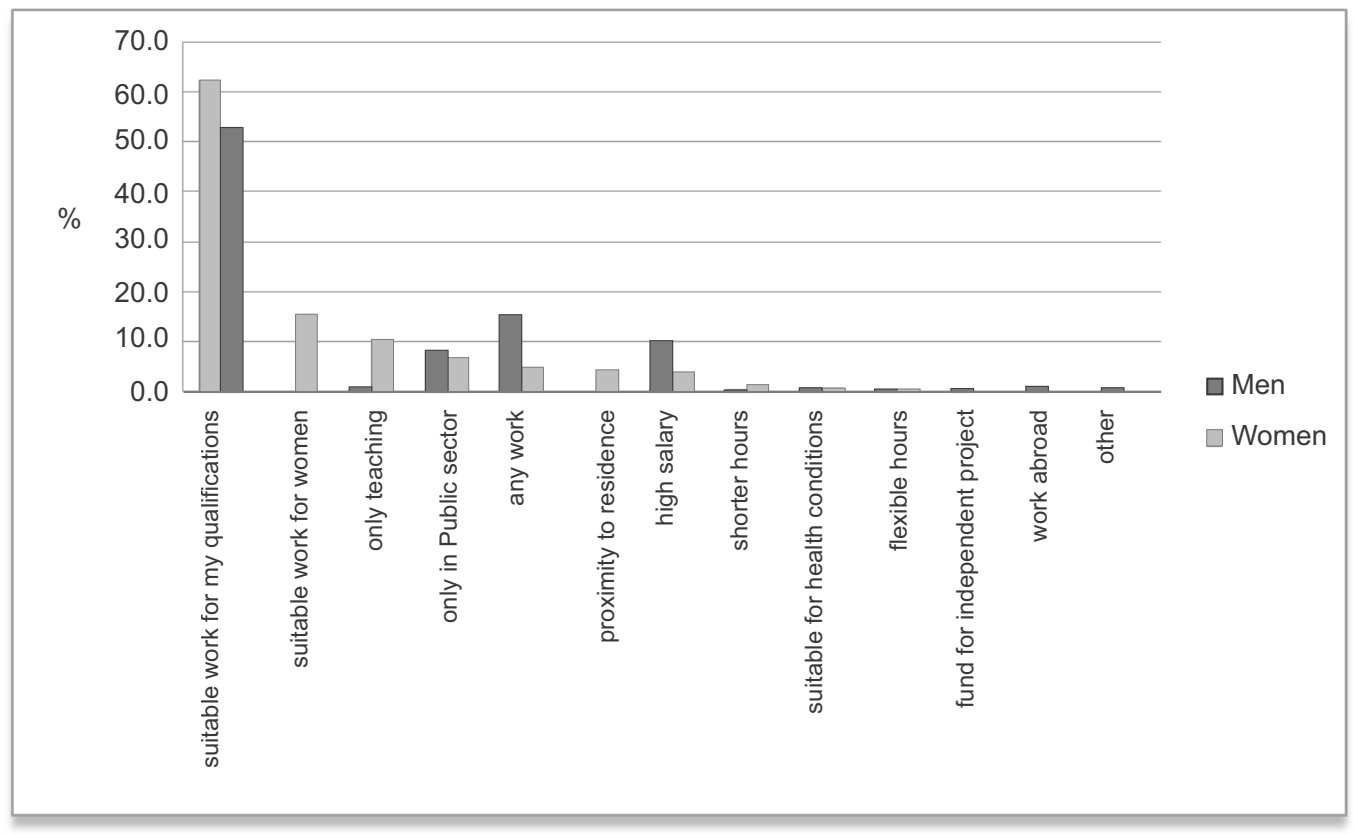

Source: The Palestinian Central Bureau of Statistics PCBS, 2006, Database of the survey of the state/conditions/ situation of graduates 2006, Ramallah, Palestine. 
In terms of the specialization and its impact on attaining jobs shows that the rate of unemployment among graduate women aged 20-34 years is the lowest in the medical and health care fields, where the rate is $36.5 \%$, compared to $52 \%$ in technological fields, such as engineering. The unemployment rate among male graduates is lowest among professionals in the humanities, and the highest is among the fine arts and applied arts (see Figure 7). These indicators show the impact of the different disciplines in the attainment of jobs, especially when compared with the bulk of graduates for each discipline. It also shows that the highest category among the female graduates is concentrated in the disciplines of humanities, business, and management sciences, while male graduates are concentrated in the disciplines of business, administrative and engineering sciences (see Figure 8).

Figure 7: Unemployment rate among the graduates of community colleges and higher (20-34 years) in the Palestinian Territory by specialization and gender (2006).

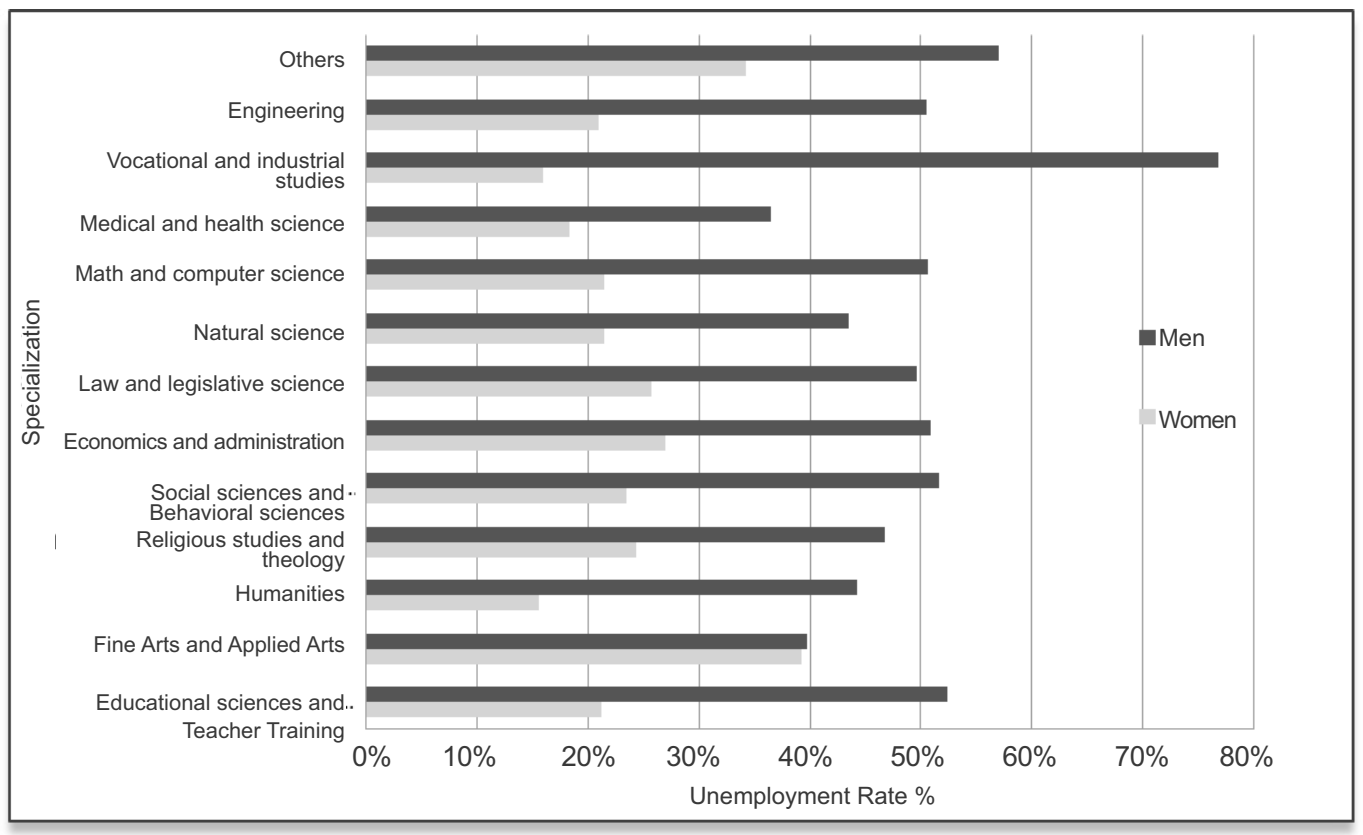

Source: The Palestinian Central Bureau of Statistics PCBS, 2006, Database of the survey of the state/conditions/ situation of graduates 2006, Ramallah, Palestine. 
Figure 8: The percentage distribution of graduates of community colleges and higher levels of education (20-34 years old) in The Palestinian Territory by specialization and gender.

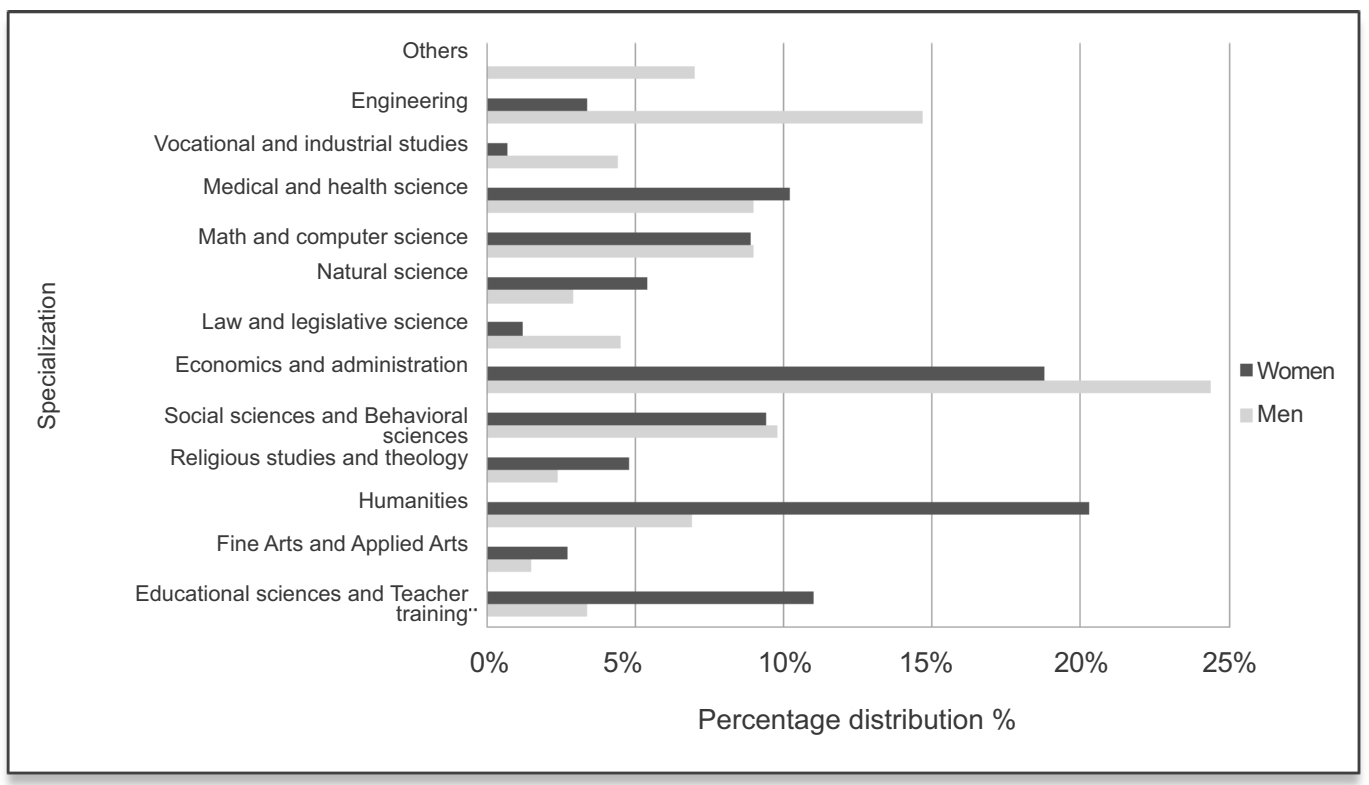

Source: The Palestinian Central Bureau of Statistics PCBS, 2006, Database of the survey of the state/conditions/ situation of graduates 2006, Ramallah, Palestine.

Regarding the economically active female graduate (i.e. workers), the distribution by type of their attainment of jobs (paid, unpaid, and self employed) did not change over the past ten years (1999-2008). The proportion of graduate females who have paid work is $95 \%$, and the remaining percentage is distributed evenly between workers without pay and self-employed while the proportion of self-employed workers among graduate males decreases and the percentage of those who have paid or unpaid work increases. On the other hand, the percentage of self-employed, among non-graduate women, increased from I0\% to $17 \%$, compared to the slight decline in the rate of women with or without pay reaching a percentage of $43 \%$ for self-employed (those who have paid work), and $40 \%$ for those working unpaid. Therefore, we can note that the graduates of both genders (sexes) tend to move toward paid posts more than others, and most non-graduate women focus on unpaid work in the home, while non-graduate men prefer other activities and entrepreneurship. But the discrepancy between the rates of graduate men and those with low education in paid employment remains slight, compared with women, where there is a wide difference, since the proportion of non-graduate women who have paid work is less than half of the graduate females. This is a clear indication that graduate women mostly search for paid employment (see Figures 9 and Io). 
Figure 9: Percentage of unpaid family workers out of total workers by number of years of education and gender (2008).

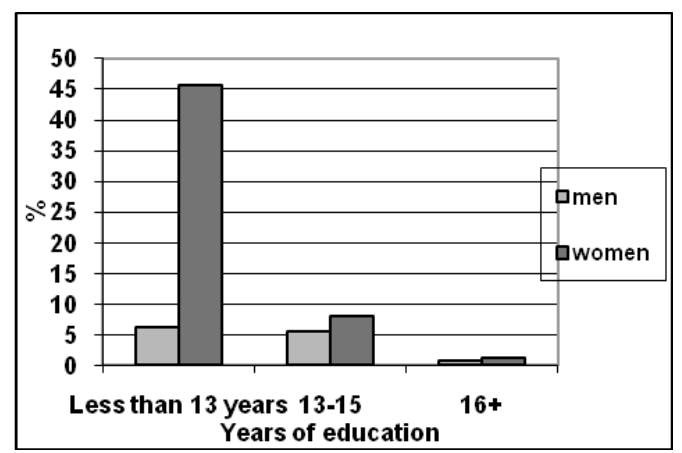

Figure 10: Percentage of wage employees out of total workers by number of years of education and gender (2008).

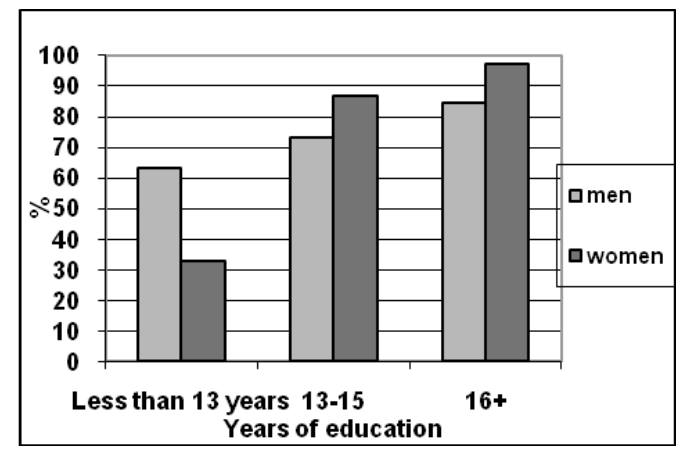

Source: The Palestinian Central Bureau of Statistics PCBS, 2009, Database of the survey of the workforces, 1996-2008, Ramallah, Palestine.

The results show that $20 \%$ of women $\left(20^{-} 34\right.$ years old) of the total employees were working in the government (public sector) in 2008, almost equal to that of 1999 ( $19 \%$ ). It should be noted that the government employs almost half of the graduates, which implies the weakness of the private sector to employ/absorb sufficient proportion of the graduates, especially in such a high rate of unemployment.

Regarding the wages, it is noted that the wages of young people with a low level of education before the Al-Aqsa Intifada were higher than the wages of graduates at that time. This is because a large proportion of nongraduate men worked in Israel and the settlements, which raised the overall level (average) of wages. But this had a negative impact on education, since that situation encouraged and attracted young people to drop out of school to work in Israel at that time. This situation continued until the Al-Aqsa Intifada, when the Israeli occupation authorities prevented Palestinians from working in Israel and the settlements. This policy lowered the percentage of workers in Israel and increased the level of unemployment, thus a significant proportion of the unemployed became people with a lower education.

On the other hand, the results show that the wages of young men are much higher than those of women. This is mostly due to the fact that young men often have jobs with higher financial returns. For example, salaries paid to either male or female employees in the government (public sector) depend on a specific career scale, and a distinction between the genders cannot be made in every step of the scale. But the careers held by women in the public sector are mostly in the lower scales, whereas men occupy careers mostly with higher scales. Where the contribution rate of 
women in the lower positions of the public sector (degrees $\mathrm{I}^{-} \mathrm{I} 2$ ) is up to $65 \%$, while the proportion of occupation of higher posts, such as director level $\mathrm{C}$ and higher does not exceed the rate of $24 \%$.

By reading the preliminary statistical data covering the nature of employment opportunities for both genders and the nature of jobs offered, it is clear that Israel's job market is available for men, especially those with a low education level.. While agriculture is the main sector for nongraduate women, it appears from the results that unemployment is low among non-graduate women due to their small number and orientation to non-skilled works such as the agricultural sector. The results show that the female graduates tend to work for pay, more than $90 \%$ of female graduates work in paid employment and, in particular, the public sector, as compared to $75 \%$ of male graduates.

With regard to work in the informal sector, a report by the International Labour Organization (Hilal, AL-Kafri, Kuttab, 2008) discusses the "non-protected work" in the Palestinian Territories and shows that the percentage of women working in non-protected and irregular jobs was $47 \%$ in 2006 , compared to $53 \%$ among men. This is an indication that women are often trying to get formal and regular jobs at the beginning to ensure their rights, and when this is not possible, they either come out of the labor market or accept what is available; unlike men who will accept any work instead of going out of the labor market, as will be shown during the analysis in the following section. It should be noted that the percentage of women working in the informal and irregular sector is considered high compared to their small number.

\section{Transition Probability Matrix}

In order to identify the movement of individuals between the ages of 20 and 39 from full-time education to employment or full-time household duties, a transition probability matrix (TPM) of the data from the Labor Force Survey was carried out quarterly by the Palestinian Central Bureau of Statistics PCBS since 1995 using the period between 1999 and 2008 . The data for 1999 to 2000 has also been used to study the movement before Al-Aqsa Intifada and to link the data with the post period to identify the nature of the movement of individuals before, during, and after Al-Aqsa Intifada. The development of the labor market during those periods was already discussed.

The Labor Force Survey provided a quarterly database, which monitored individuals in the labor market for a year-and-a-half. The families were visited for two consecutive quarters, and then ceased to be visited for 
two consecutive quarters, followed by return visits for two consecutive quarters, tracking the movement of family members within a year-anda-half. The manpower survey provides a fundamental database for the characteristics of individuals in the labor market, their demographic characteristics and their social and educational levels. In this survey the international concepts of Labor Statistics adopted by the International Labor Organization were utilized.

Under normal circumstances, individuals move from full-time studies (non-participants in the workforce) to the labor market or to full-time housekeeping work. The latter applies especially to women. With the former-movement to the labor market - the individual has two alternatives. The first possibility is to search for work and continue the search until jobs have been found, initiate jobs for self-employment, or have unpaid family work. The second alternative is to go out of the labor market, this happens especially with women. There are several possibilities but their probabilities cannot be estimated separately. Therefore, the transition probability matrix was used to determine the likelihood of transition from one state to another among both men and women, in order to understand the behavior of each gender., The aim of this analysis was to form an initial concept of the factors that affect levels of unemployment among young graduate women. In addition, it was continue to track graduates for a period of time to identify the functional changes that happened after getting the first opportunity after graduation. Hence, a graduate group $\left(20^{-} 39\right.$ years old) was studied.

On the other hand, to see the impact that levels of education for both genders have on their movement in the labor market, or their movement from outside the labor market to the labor market or vice versa, individuals have been divided into three categories according to their level of education (i.e., not currently enrolled in education). The categories are:

- Level I: individuals who have completed I2 years of schooling or less

- Level II: medium diploma holders (I3-15 school years)

- Level III: higher education (i6 years of schooling or more)

To obtain accurate and optimized identification of individual transition, an individuals' state has been divided into the following six groups:

I. Self-employed persons - employers of at least one paid worker, and the self-employed

2. Unpaid worker as family members

3. Paid workers 
4. Unemployed

5. Students not participating in the workforce

6. Non-participants in the labor force for other reasons-economically inactive

\subsection{Results of Transition Probability Matrix (TPM) Analysis}

The probability to move from one state to another for both genders was studied on the basis of the three levels of education for comparison purposes.

The results show several interesting facts about gender (see figure II). The first story reflects the extent of discrimination against women in terms of positions or types of employment females occupy compared with males. Whenever the level of education among women is lower, the market demand for them is higher, and if the level of education among them is higher, the market demand for them is lower. On the contrary, this situation is reversed among men. Women, who receive a community college diploma are less likely to be unemployed, and the unemployment rate of men who have the same educational level is higher. This means that the demand for women who have a diploma degree is high due to the low number of those at this level of education who seek a job. The discrimination is apparent here through the employers' demand for women who hold a diploma and males who hold bachelor's degree or higher, despite the convergence of the number of graduates of both sexes in both levels of qualifications. This trend reflects the culture of the community regarding professions and gender; where the general idea is that women are more suitable and perform better in professions that only require a diploma degree, such as secretaries, administrative assistants, kindergarten teachers, nurses; whereas occupations that require a higher level of education are more suitable for men. Also, a study was carried out by the Palestinian Women's Research and Documentation Center (2009) showing the existence of prevalent ideas about the sectors and occupations that can be occupied by women. It will require extra effort and successful models to change and break down this cultural norm. The analysis of the results shows that the probability of unemployment among women who have diploma degree is $16 \%$, while it is $40 \%$ among women who have a bachelor's degree or higher. While unemployment among young men who have diploma is $35 \%$, it is $23 \%$ for those who hold a bachelor's degree or higher. The high probability that graduate women with a bachelor's degree and above has to join the unemployed is resulting in despair and subsequent negative effects on women, thus, losing the enthusiasm to continue searching for work and therefore they become out of the labor market. 
Figure 11: The probability of individuals' (20-39 years old) transition from full-time education to one of the six categories by gender and educational level.

First level: individuals who finished 12 years of education or less

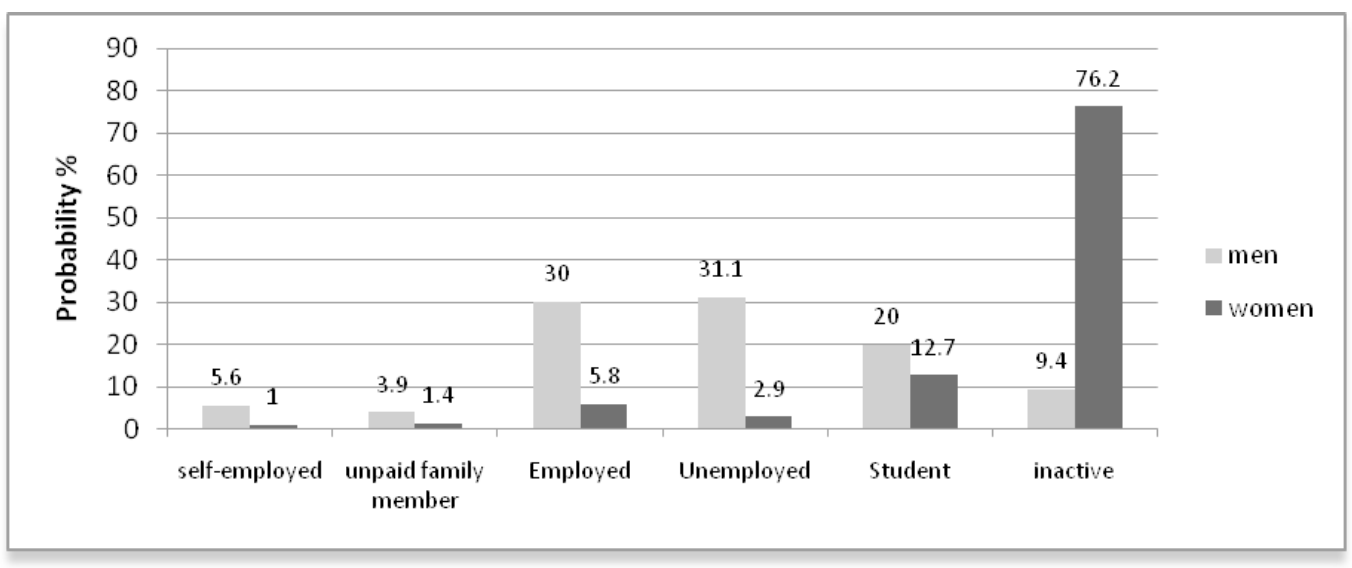

Second level: individuals with diploma degree (13-15 years of education)

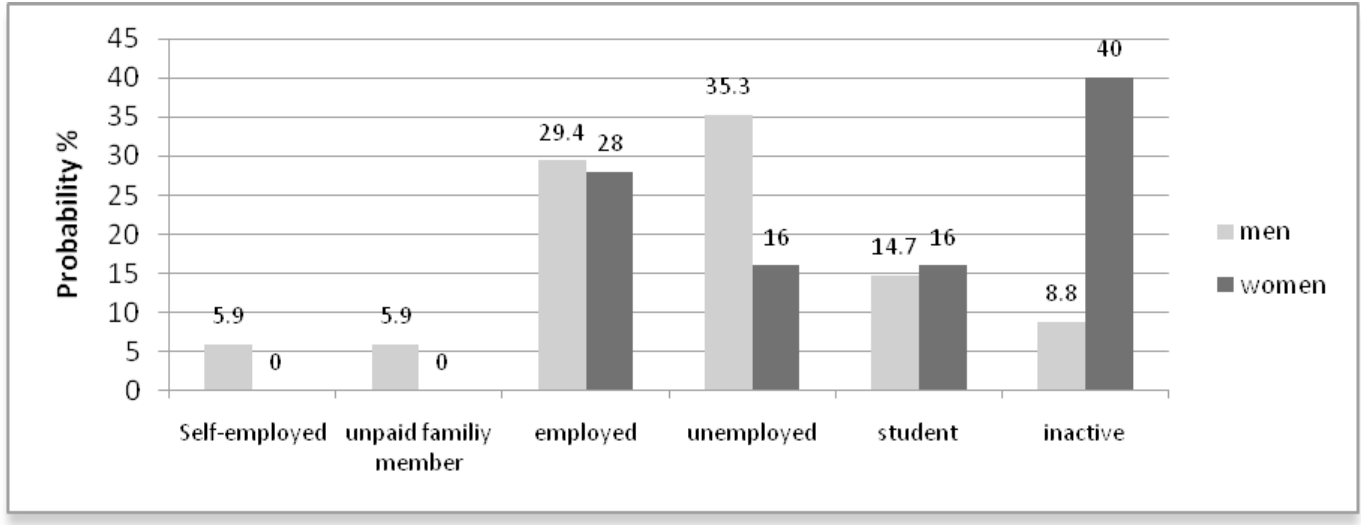

Third level: individuals with a bachelor degree and higher education (16 years and more)

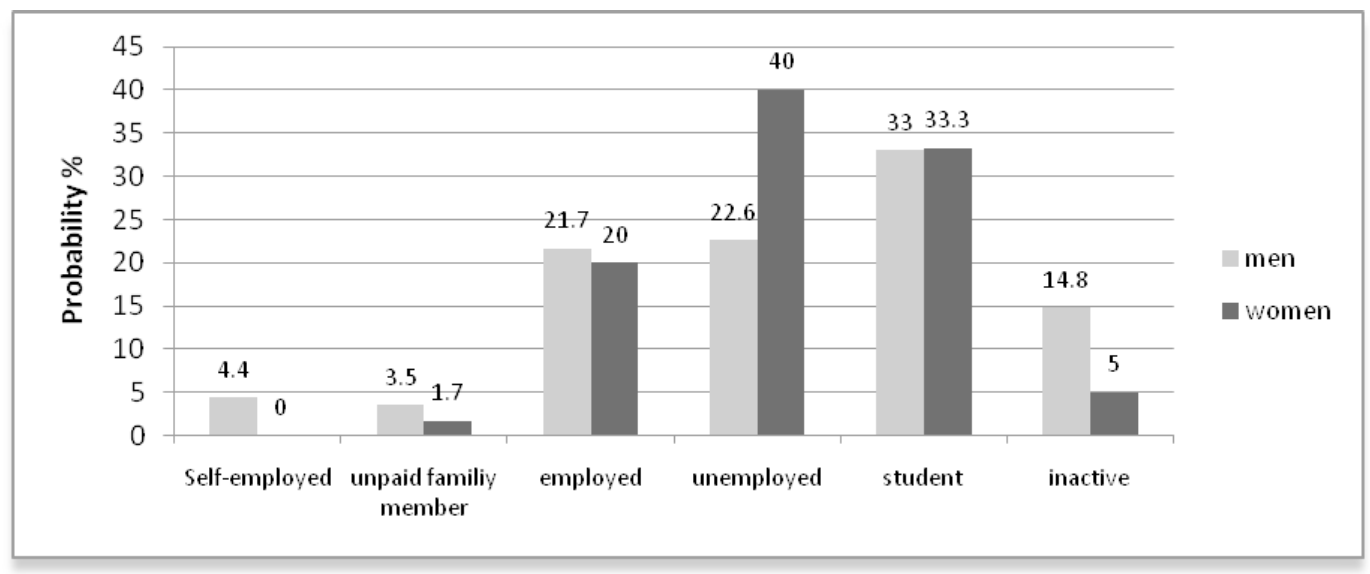

The second fact which can be observed in Figure II is the apparent strong correlation between the educational level of women and their participation in the labor market. This explains and confirms the basic role 
of the family in the participation, or not, of women in the labor market. The family decides whether to let a female pursue higher education and this in turn affects her future employment. The family decides for the woman to quit her study before finishing the high school, regardless of the reasons (e.g., financial, cultural, or/and social) behind this decision. But if the family decides that she can continue her studies after high school, then they are convinced of her likely participation and involvement in the labor market. There are rare instances where the family considers that the importance of education for a woman is to secure her future with her husband and her future family (Palestinian Womenss Research and Documentation Center, 2009). The possible alternatives that a woman has are clearly depicted in Figure I2. The figure shows one of the reasons for low participation by women, which is the difficulty to obtain a job that is suitable for them, thus increasing the duration of the research for work and thereafter leading them to stop searching for work and being out of the labor market.

Figure 12: The most possible alternatives/tracks for young people by gender

Young women

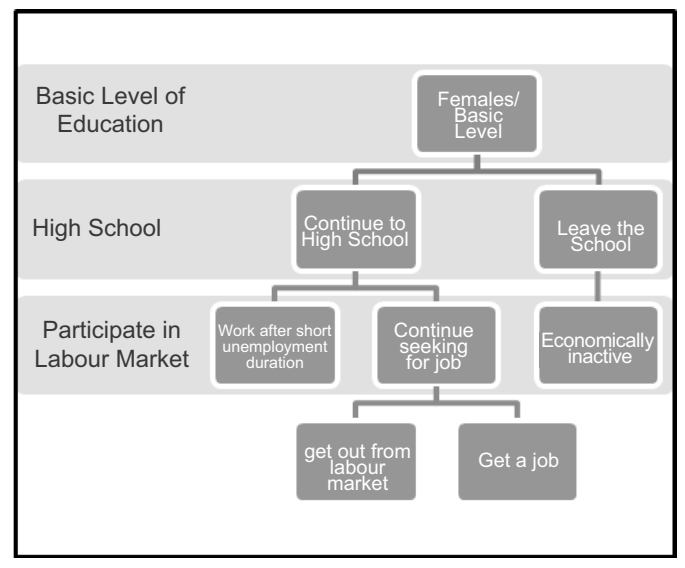

Young men

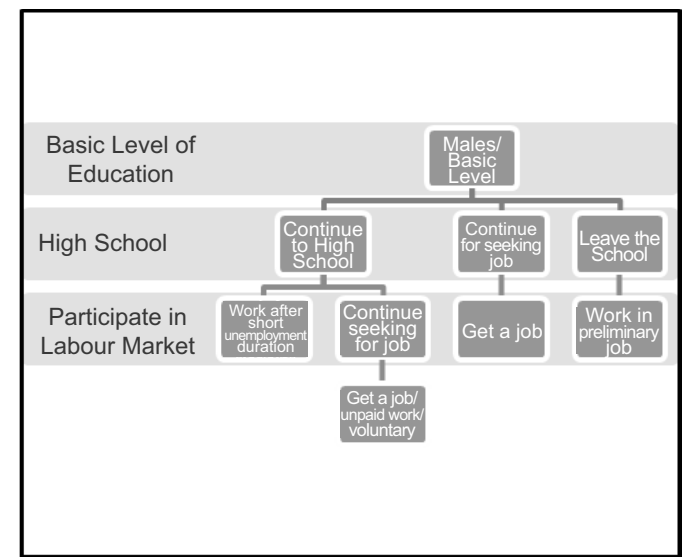

As shown in Figure II, the better educated a woman is, the greater is the probability of their job retention. This is due to the family belief that their investment in education must be rewarded by economic benefits, or that work is a right for women and thus education is a way to enable and empower them. The probability that a woman will leave school before ending high school and transition to the labor market is very low (I \%), compared with the possibility of $44 \%$ that she finishes her diploma ( $13^{-1} 5$ years) and transfers to the labor market. Also, the probability that a woman gets a bachelor's degree 
or higher is up to $62 \%$. For men, the situation is different, where the probability to leave school early and go to the labor market has reached $7 \mathrm{I} \%$, which is a relatively high probability. This was one of the prevailing phenomena in the years preceding the Al-Aqsa Intifada II, where young people left academic education early for work in Israel due to their belief that the return from the work after finishing education is lower than the return from working in Israel and settlements (AL-Kafri, 2003). Also, the probability of transition to the labor market by male diploma graduates was $77 \%$, and for the young men holding a bachelor's degree or higher the probability is $(52 \%)$, where there is a possibility of $33 \%$ that they continue their education.

Figure II indicates that the young male graduates with a diploma or higher are more likely to get jobs than women. Whereas the probability of young, diploma holding men getting a job opportunity is up to $4 \mathrm{I} \%$ and $28 \%$ for women. While the probability of obtaining a job opportunity for the graduate with a bachelor's degree is $30 \%$ for men and $22 \%$ for women. This difference is primarily due to the variety of opportunities in the labor market for men, especially through the creation of opportunities for work or self-employment through family projects. Otherwise, the probability of get a job is somewhat equivalent for men and women.

The continued search for work and the length of unemployment negatively affects the graduates, particularly girls. Figure 13 clearly shows that the continued search for work without success raises the level of despair. The probability that unemployed graduates will continue their search for work is comparable between men and women, ranging from $53 \%$ to $62 \%$. But for those who have changed their situation from unemployed to another state, the matter seems to be substantially different. The probability for women to obtain work, within a continuous period of job seeking is much less than for men, since the probability of finding jobs for both men and women holding diploma degrees is up to $38 \%$ and $13 \%$ respectively, and for the holders of bachelor's degrees and above is $33 \%$ and $20 \%$ for both men and women, respectively. This is an indication that men are more likely than women to get a job after a period of job searching. This is because of the existence of a variety of options for men such as self-employment, while women mostly do not have such an opportunity.

Concerning the probability that people will quit searching for a job because of their despair in the labor market, we find that women are less tolerant than men to stay in the labor market and job search. The probability of quitting from the labor market is higher among females compared to males regardless of the educational qualifications. 
The probability that female graduates (holding a diploma degree) will quit searching for a job in the labor market after a period of unemployment is up to $33 \%$ compared to only $5 \%$ among males. For the female graduates with bachelor's degrees or higher, the probability of leaving the labor market is up to $17 \%$ against $7 \%$ of male graduates. Recalling that we referred to quitting the labor market as the despair of not finding a job, because people are convinced to look for jobs at the beginning, and stop their search mainly due to desperation even if there were other reasons, such as the full-time involvement in a household or marriage.

On the other hand, it is clear from the mentioned ratios that women holding a diploma who leave the labor market after a period of time in the job search are higher than the ratios of females who hold higher qualifications. This confirms that the more the investment in education is, the greater the adherence to obtaining a job will be. In a survey about the circumstances of graduates of higher education and vocational training, which was carried out by the Palestinian Central Bureau of Statistics PCBS in 2006, shows that the average period of unemployment for diploma graduates during 1987-2005 was higher than graduates with bachelor's degree or higher for both sexes. Whereas the period of unemployment for graduate males (holding diploma) is higher than for females, as the patience of females is less than that of males which makes them quit the labor market when they find it difficult to get a job.

Comparing Figures II and $\mathrm{I}_{3}$, it seems that the probability of getting a job by the recently graduated females with a diploma and those who did not engage in search activities for a long period is higher than for graduates with a bachelors degree or higher, while it is vice versa in the case of longer job search periods (unemployment). The reason behind this can be the requirements and special conditions and the nature of the posts of the graduates of higher education (bachelor and above) is higher than the requirements of diploma holders, which prolongs the period of job searching for graduates of higher qualifications and thus results in higher rates of unemployment among them. This applies to males but is less severe. On the other hand, the comparison shows, the enthusiasm of women at the beginning after graduation to participate in the labor market, but the level of this enthusiasm declines gradually after a period of searching for work and not being able to get it. Here comes the role of society in responding to the youth needs to get a job, and in particular immediately after graduation. A new study suggests that the most important reasons for inability of recently graduated young people to find jobs is to meet the requirements of the labor market for the availability of expertise, which of course is not fulfilled by the new graduates (Palestinian 
Women's Research and Documentation Center, 2009). This requires taking this into account by the employers, trying to recruit new graduates and replace the experience requirement by creating it through training them in the workplace, or by the decision makers by adopting policies that qualify graduates with minimum experiences in order to facilitate their mission to get a job.

This brings us to research on the impact of the vocational training in the workplace or training courses to help graduates in finding jobs or mitigating the lack of experience they have. A new study reports that those who have access to such courses are more able to get jobs, it also raises the participation of women in the workforce (Edwan, 20IO). But in return, after an investigation into the training courses received by the graduates by gender, it was found that females are often less likely than males to receive training courses, while females who obtained their master's and postgraduate diploma's are more likely than males to access vocational training. This may be due to the low number of women that hold certificates higher than a bachelor's degree. Thus, females in general are missing the empowerment by training, vocational and technical education compared to males.

Figure 13: Probability of individuals' (20-39 years old) transition from unemployment to one of the six categories by gender and educational level

First level: individuals who finished 12 years of education or less

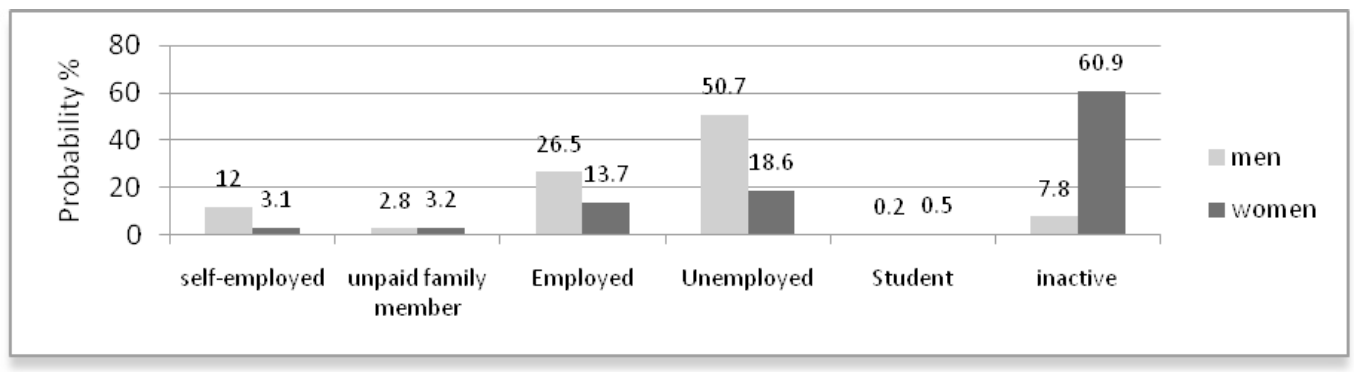

Second level: individuals with a diploma degree (13-15 years of education)

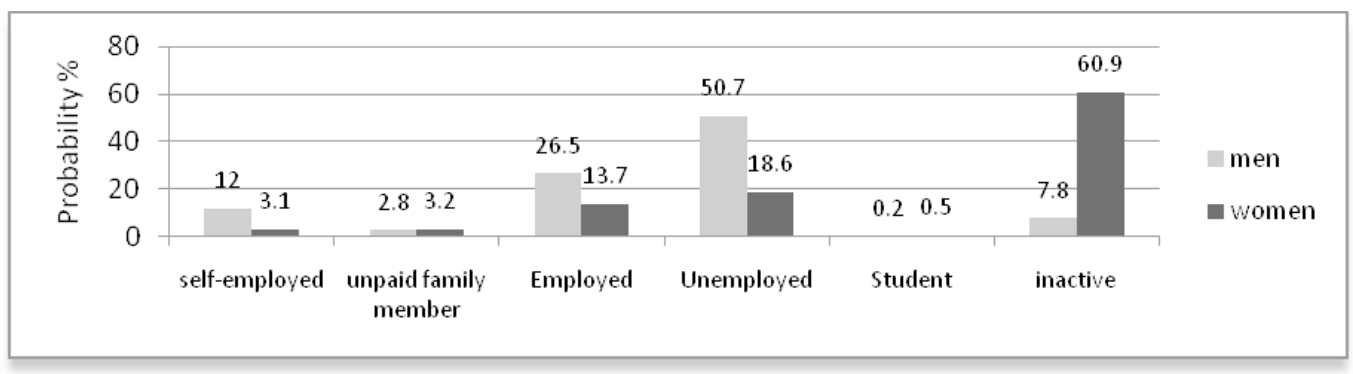


Third level: individuals with Bachelor degree or higher education (16 years and more)

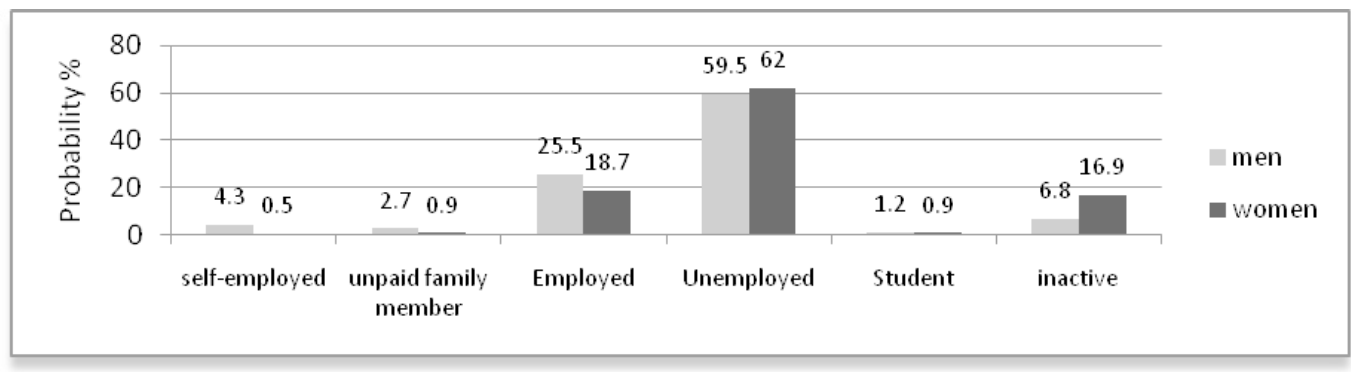

Vocational training and short-term training could empower every person, regardless of his educational level, to obtain a skill in a profession. Thus, graduates, who we focus on in this study, are those who get a diploma and above. Also, we include a category of young people who have not completed their education after high school, but at the same time enrolled in vocational training courses for different periods up to one year. It is important here to refer to them. It is necessary to refer to people with low education not only those with certificate of academic school, but it is possible that they have certificates of vocational training. The results of the 2007 census show that individuals who received a high school certificate and received vocational training (such as carpentry, blacksmithing, electricity, construction, etc.) have reached $13 \%$ for males and $8 \%$ for females. As well as $12 \%$ and $7 \%$ for both females and males who had a middle school education and received training. We found that the vocational training had direct impact on reducing levels of unemployment among members of that group of young people. This is shown in Figures II and $\mathrm{I}_{3}$, it is clear that the probability of getting a job was high for this group of young people compared to graduates with a diploma or higher, especially among males.

Regarding individuals outside the labor force for reasons other than a full-time study, the question is whether graduates move directly from school to economic inactivity, such as full-time work at home (housekeeping). In fact, the answer is yes, especially among women. Figure I4 clearly shows that female graduates with a bachelor's degree or higher move after graduation out of the labor market to take care of their own family members, whether they are married or single. But after a period of time and after stability they participate in the workforce (become involved in the labor market). The probability that they return to the labor market reached $34 \%$, which is a quite high percentage when compared to the percentage of those who received a diploma or below, which is about $15 \%$ and $5 \%$ respectively. Here, it can be concluded that investment in education was mainly to take advantage of education to 
support the family economically, and this is the conclusion of a study of the Palestinian Women's Research and Documentation (2009). Even though the girls move from the university to outside the labor market (economically inactive), there is a high probability of involvement in the labor market later, especially under the difficult economic conditions in the Palestinian Territories. This state of being economically inactive, leads us to the following question.

Do these graduate women face a difficulty in getting jobs after being economically inactive? The answer is of course, yes. Figure I4 compared with Figure II, shows that women who have had bachelor's degree qualification or higher, and approach the labor market after a period of being economically inactive (by international definition) face a higher possibility to be unemployed than those who move directly to the labor market. The probability of being unemployed is $24 \%$ compared with I6\% for women who entered the labor market after a period of being economically inactive and who entered the labor market directly after graduation, respectively. Hence it can be concluded definitely that one of the reasons for the high levels of unemployment among female graduates is looking after the family, or because they get married during or after graduation. Of course, this is an expected result, since the labor market is looking for workers with experience, which can be obtained only from their previous work, or recent graduates with solid and fresh technical/ professional information.

Figure 14: Probability of individuals' (20-39 years old) transition from non-participation in the labor force for reasons other than full-time engagement in the educational process to one of the six categories by gender and educational level

Firs level: individuals who finished 12 years of education or less

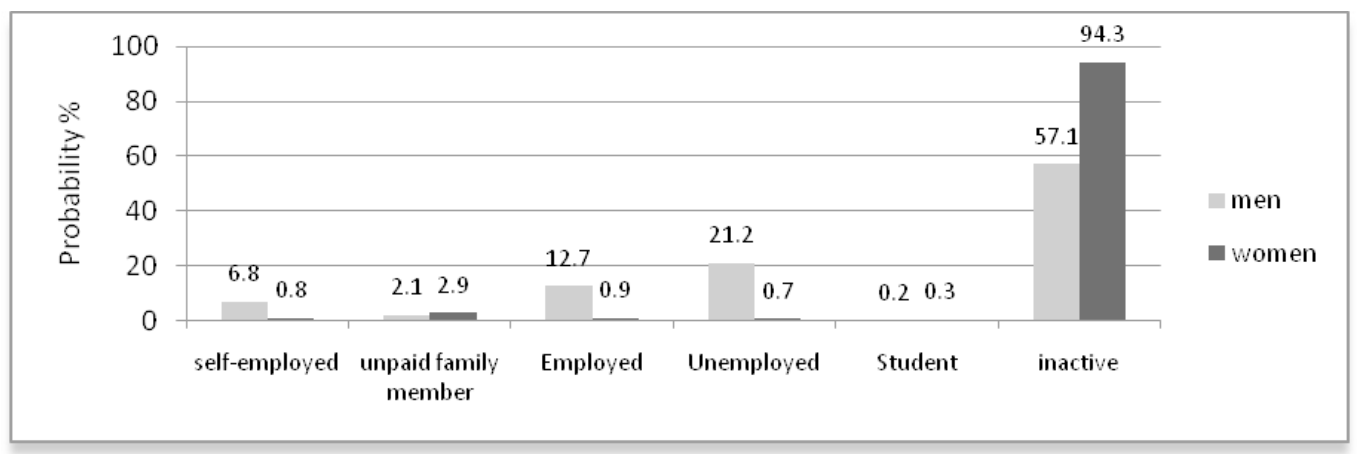


Second level: individuals with a diploma degree (13-15 years of education)

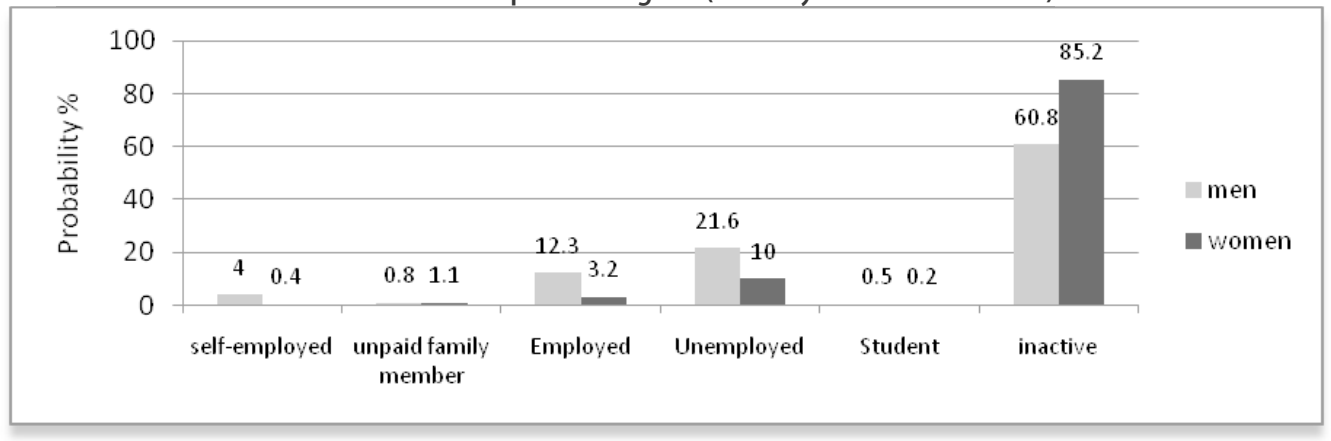

Third level: individuals with Bachelor degree and higher education (16years and more)

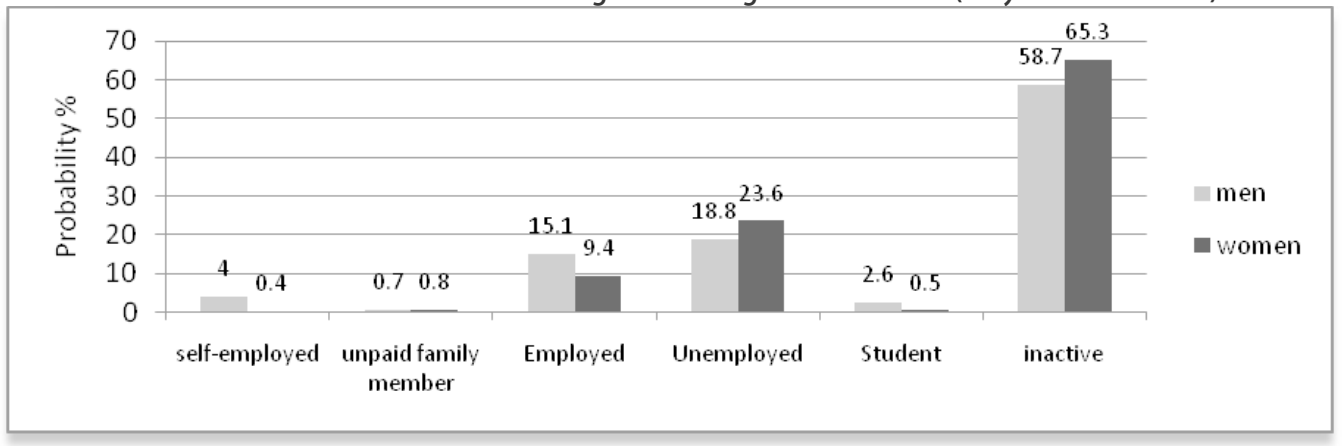

On the other hand, as a complement to the above, the higher the educational qualification is, the higher the possibility of a return to the labor market for women. This explains the feasibility of their return, especially under the difficult circumstances in the Palestinian Territories and the scarcity of jobs. Thus, higher education empowers women to obtain better income than other graduates with lower levels of education. Therefore, their decision to return to the labor market is more feasible than the decision of other women. Unlike women, the probabilities to get a job opportunity or to be unemployed are almost similar for all categories of male graduates and all transitions (from university, institute, unemployment, economically inactive etc.), and the differences are negligible. 
Figure 15: Probability of individuals' (20-39 years old) transition from paid employee to one to one of the six categories by gender and educational level

Firs level: individuals who finished 12 years of education or less

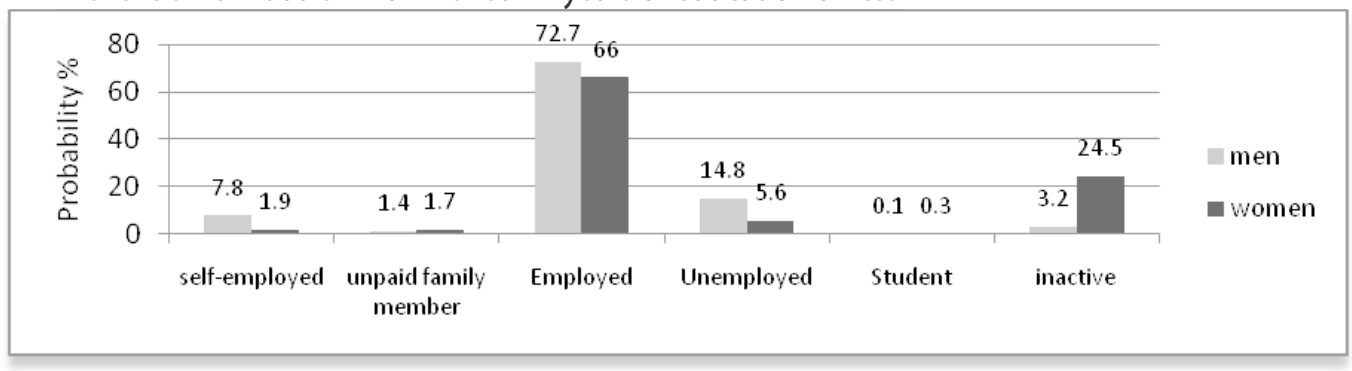

Second level: individuals with diploma degree (13-15 years of education)

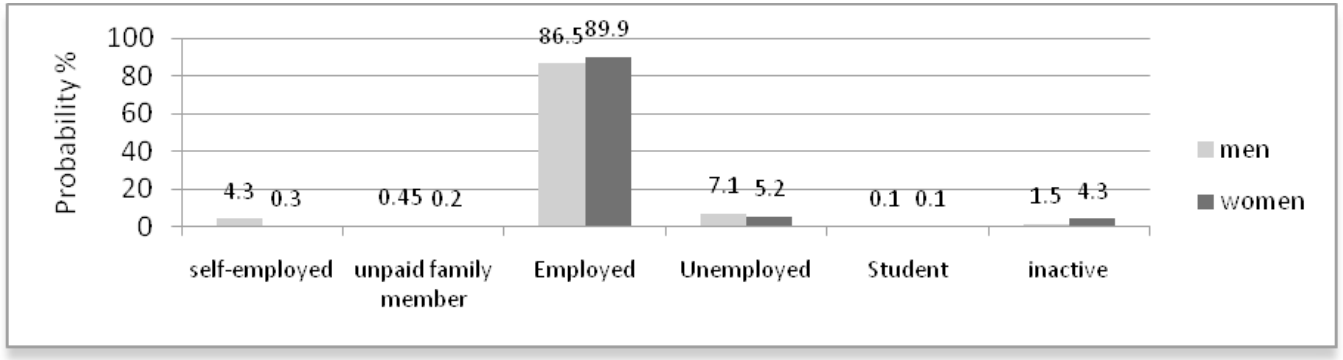

Third level: individuals with Bachelor degree and higher education (16years and more)

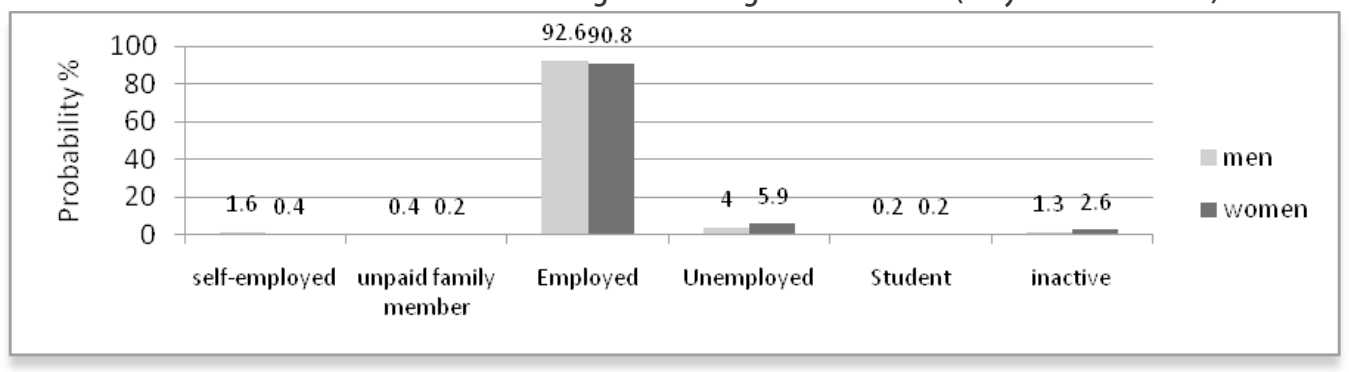

We now turn to another subject which is close to the concept of job rotation. Figure 15 shows the probability of the stability of the employees in their jobs regardless of gender. It is clear that job stability applies for both, the more the education qualifications are, the more stable the job is. The probability of unemployment for less educated people is high compared with others, especially for men, where the corresponding higher probability to exit from the labor market for women. This shows how the importance of higher education is to the stability of the job for young people. This is confirmed by the transition of most individuals with low degrees of education (no more than high school) from employed to unemployed at the end of 2000 i.e., the beginning of the Al-Aqsa Intifada and the beginning of the Israeli measures and restrictions against the Palestinians and preventing them from working in Israel. 
In comparison between males and females, it is noted that the differences are close, but points to some issues that are important to be addressed due to their relationship to high unemployment rates among graduate females when compared to the graduate males. Figure 15 shows that the probability of job stability for graduate females with a diploma is slightly higher than for males with the same educational level, where females have higher rate of quitting from the labor market, while males have higher rates in transition to unemployment. But for holders of higher degrees (Bachelor and above), there was a possibility that the job stability for females is less than for males. This helps in adding other factors (the factor of stability) to explain the high unemployment rate among graduate females.

Working as an unpaid employee in a family project is often an alternative for a graduate who has a family project until he gets a more durable paid job. Otherwise, graduates work permanently in family projects whenever they are satisfactory to them. And therefore stability does not appear as in a paid work. The probability of stability in unpaid work for the family ranged between $40 \%-50 \%$ as shown in Figure 16 . This confirms that working for the family is not an alternative since it is a family duty. Thus, if an individual wants to continue, often he will have what he wants, otherwise, he can quit this job, especially young men. This culture, scattered mainly in the southern region, is a culture of family work and adopting father's career (Jafari, 2007). Now regarding the educational level of youth, females with academic qualifications that do not exceed the high school (secondary certificate) level have two essential alternatives/tracks/options, either to continue with unpaid family labor has a probability of up to $42 \%$, or to quit the labor market with a probability of $53 \%$. While young men of the same category of education appeared to have wider options. The first alternative they have, with the highest probability of $5 \mathrm{I} \%$, is to continue unpaid work in family project, followed by either getting a job ( $16 \%$ ), or leaving the family work and searching for another job with probability of I6\% or to create his own work (be self-employed) with probability (I2\%), using a career that he could have inherited from the head of the family. Thus, we note the diversity of options for males compared to females, and this helps in the growth of productive male employment (workforce). On the other hand, concerning the young graduates, male and female, the situation is different. There is a diversity of options before them, and still with a high probability that women will quit the labor market. It was noted that the probabilities of persisting in family work for female graduates is semi-close, the difference is in the stability of the probability of quitting from the labor market after working as unpaid in the family project. It also shows that unpaid family work, as a temporary job to move to paid 
work, is less likely among women graduates than others. The probability of women quitting the labor market after unpaid work in family projects is up to $36 \%$ for diploma graduates, and $18 \%$ for female graduates with a bachelor's degree and higher. The results here confirm that the higher the educational qualification level of females, the harder they try to find a job due to the investment made in their education. This is a reference to a clear difference in the culture regarding women's right to work or that her work is based on economic needs, and the demise of this need lets the motives for the participation of women in the labor market disappear.

But what about the reasons for high unemployment among graduate females versus graduate males, and high unemployment among graduate females unlike unemployment among females with at most a high school qualification. It is clear in Figure I6, that the probability of the survival of women holding qualifications below the bachelor's degree in the labor market, if they decide to leave unpaid family work, is very low compared with women with a bachelor's degree or higher. As compared with young males holding bachelor's degrees or higher, the result indicates that the probability of survival of graduate males in family work is higher than females. Unlike women (on the other hand), when the men decide to leave unpaid family work, they have wider options. Their options are to establish their own projects, i.e. independent from family work with a probability of $7 \%$, or to get a job $18 \%$, thereby reducing the probability of unemployment more than graduate women with bachelor's degrees or higher, who often become discouraged when they do not find a job, and so stop searching according to international standard definitions Furthermore, the probability of unemployment among both males and females (holding bachelor's degrees and above) reach $23 \%$ and $26 \%$, respectively.

Stability in self-employment is much higher for males than for females. Here it should be noted that the percentage of self-employed graduate women out of the total number of working women is very low and negligible compared to men, where the percentage is up to $2 \%$ compared to $10 \%$, respectively, in 2008 . However, despite the low proportion of self-employed graduate women, they are not settled in such activities, and this is indicated by Figure 17. The probability of the stability of female diploma graduates in self-employed work is up to $59 \%$ compared with a $73 \%$ probability for men holding the same academic qualification. This probability for female bachelor's degree graduates is up to $60 \%$ compared with $74 \%$ for men with the same qualification. It should be noted that the percentage of the self-employed young people who were not educated beyond high school is much higher than the graduates, reaching the percentages of $22 \%$ and $17 \%$ for both men and women, respectively, in the year 2008. This is an indicator that the graduates are often willing 
to work in paid jobs instead of creating their own jobs and projects. This phenomenon is not healthy (this is a negative phenomenon), especially because the absorptive capacity of the government (public sector), which is the first preference for most of the fresh graduates to work in. However, it has started to decrease after being stable since its establishment in 1993.

Figure 16: Probability of individuals' (20-39 years old) transition from worker as unpaid family member to one of the six categories by gender and educational level

First level: individuals who finished 12 years of education or less

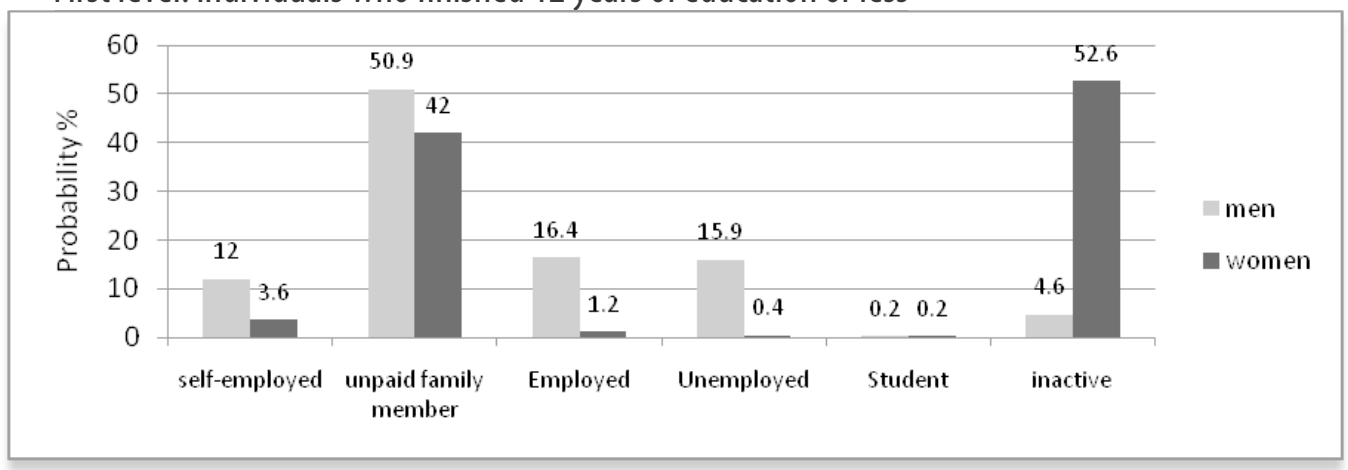

Second level: individuals with have diploma degree (13-15 years of education)

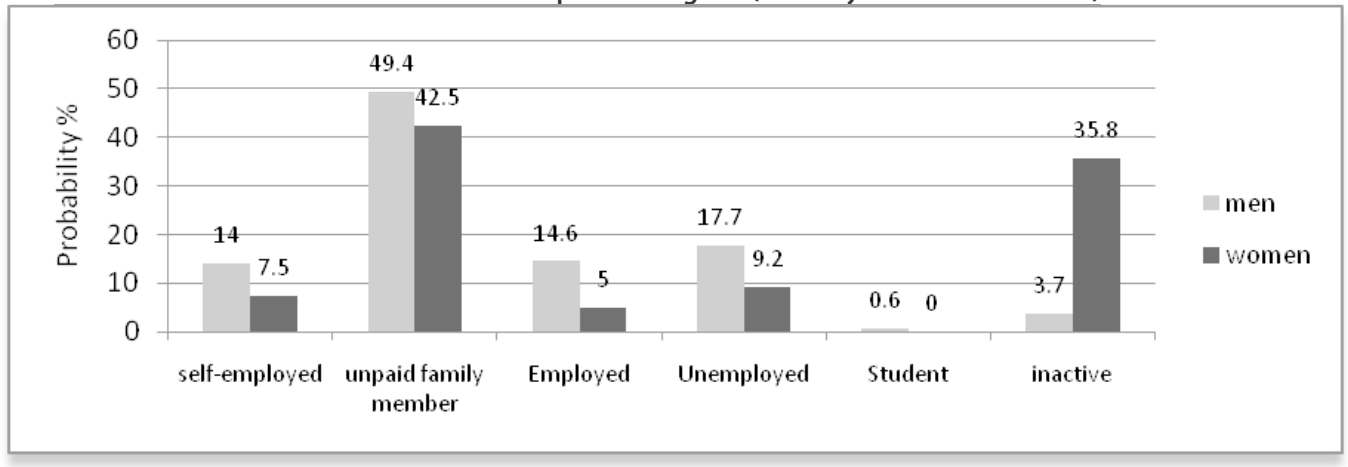

Third level: individuals with Bachelor degree and higher education (16years and more)

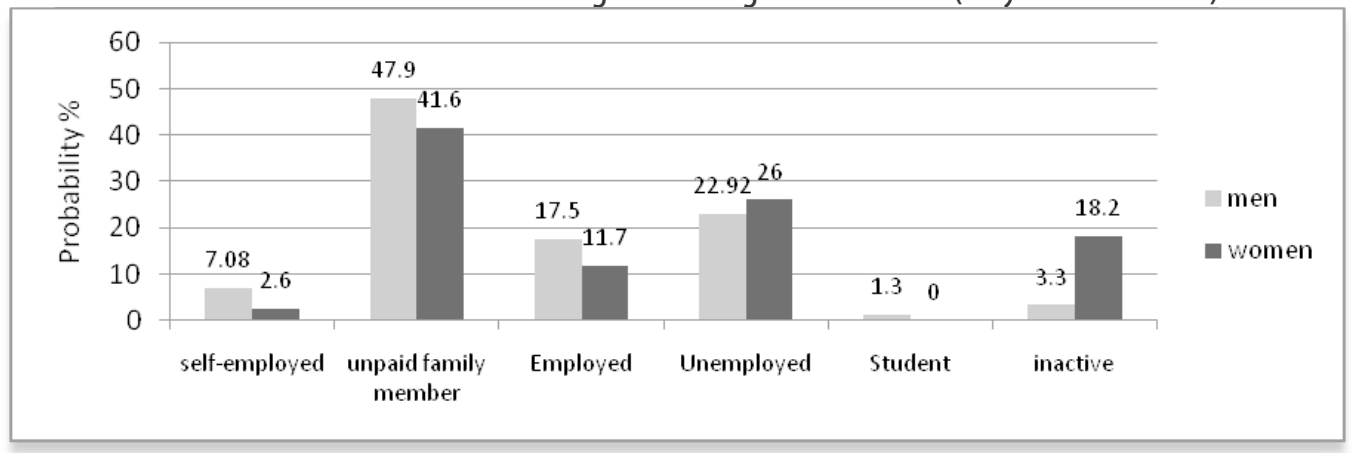


In general, some of young people who began to create their own projects (self-employment) did not settle in these projects, where some of them go to work as paid employees, search for another job i.e., or become unemployed. Women are more likely to transit out of the labor market after leaving their own business (project), but men are more likely to transit to paid employment in the case of leaving self-employment.

Figure 17: Probability of individuals' (20-39 years old) transition from self-employment to one of the six categories by gender and educational level

First level: individuals who finished 12 years of education or less

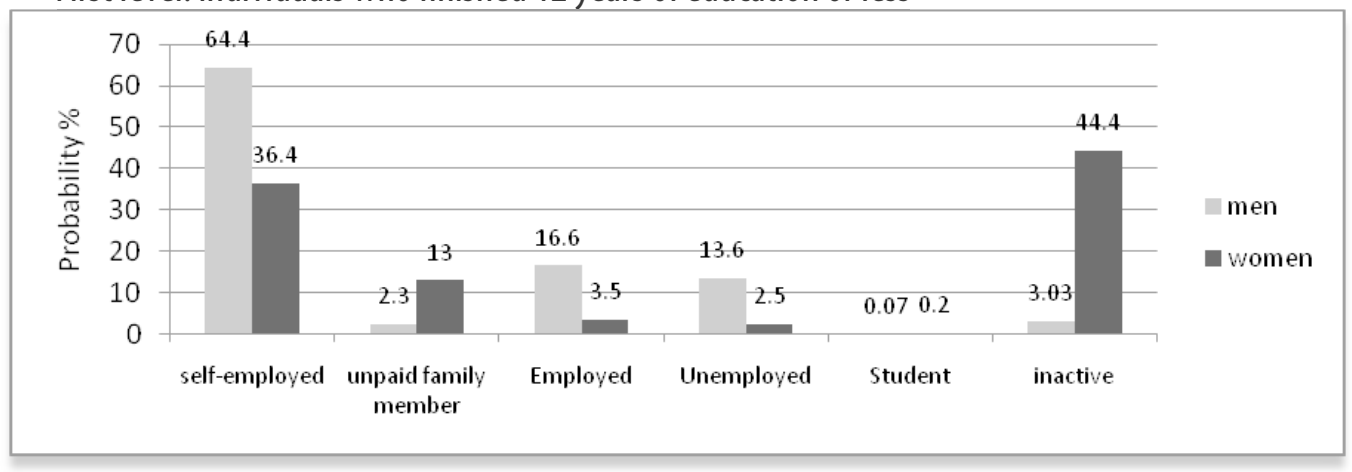

Second level: individuals with a diploma degree (13-15 years of education)

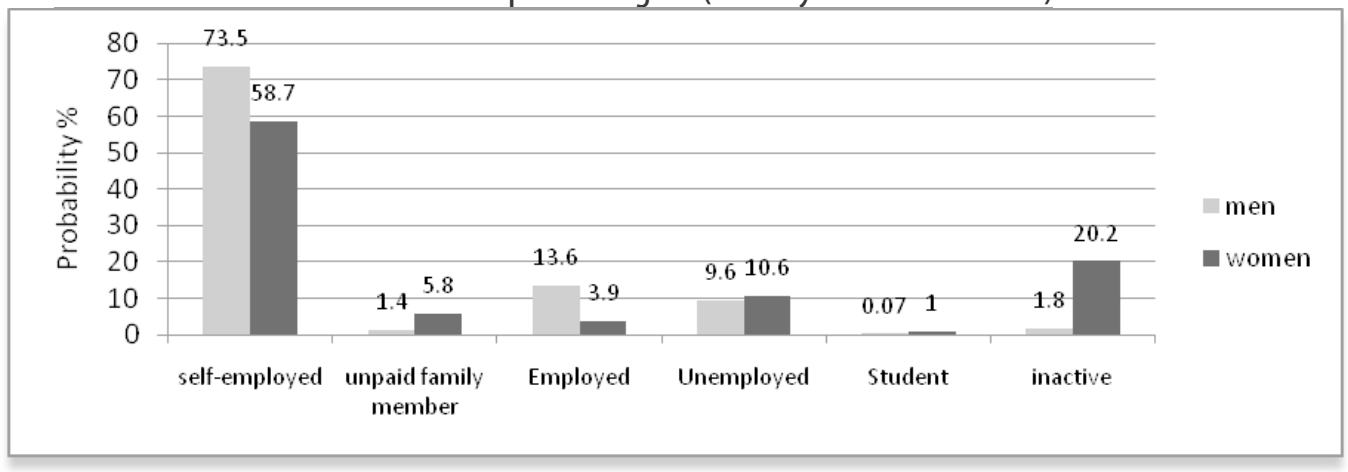

Third level: individuals with Bachelor degree and higher education (16 years and more)

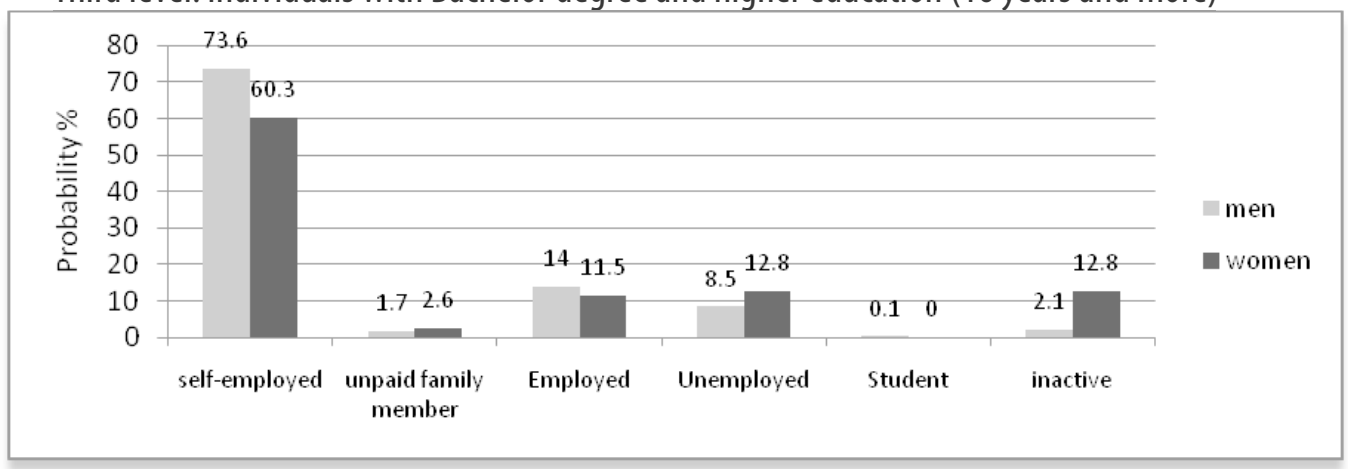


From figure I8, we can outline all forms of transitions for all young people. It shows a significant difference in transitions among all categories of men and women of all educational levels. It shows a number of conclusions as follows:

- The probability of transition out of the labor market (inactive) among women who did not exceed high school (general secondary education) is the most probable $(89 \%)$, and thus reduces the probability of unemployment (being inactive). This in turn reduces unemployment rates among this category of women and the low participation rates as well. Unlike women, the probability of transition out of the labor market (unemployment, inactive state) among men of the same educational level is very low and does not exceed $9 \%$. This can be attributed to the desperation in searching for jobs under the difficult conditions in the Palestinian Territories, which can be considered as a temporary case among men.

- The higher the level of education among women, the higher their participation in the workforce (labor force) will be. Therefore, the probability of quitting the labor market is reduced. The percentage is $89 \%$ for women who did not exceed high school, ${ }_{51} \%$ for women with a diploma degree, and $19 \%$ for women with a bachelor's degree and higher, which makes for significant gaps between educated and noneducated women.

- Unlike men, the probability of unemployment among women increases as the level of education increases.

- The results show that the probabilities of unemployment are low among women who did not exceed high school, but reaches I $6 \%$ among those who have a diploma degree, and $27 \%$ among those who have a bachelor's degree or higher, while the unemployment rate is $24 \%$ among men who did not exceed high school, $18 \%$ among those with a diploma degree, and $16 \%$ among those with bachelor degree and higher.

- The probability that male diploma graduates create self-employment (their own business) is high compared to others, while the probability is higher, for men holding bachelor's degrees or higher to get paid jobs.

- The probability of working as an unpaid family member is reduced as the level of education increases.

- The possibility of creating self-employment jobs among women decreases as their level of education decreases. 
- The probability of getting a paid job among female BA holders is high compared with other women, despite the high probability of unemployment among them, which is due to the lower probability of leaving the labor market. Hence, we can come up with a definite conclusion that the high rate of unemployment among female graduates is due to an increase in their petition for jobs under scarcity. Furthermore, this situation can lead to a big problem in the future if it continues because of their low probability to be patient to continue searching for jobs, which in turn causes them to quit the labor market early, unlike men. The above mentioned conclusion summarizes the causes that reduce the participation rates in the labor market and the high unemployment rate among female graduates in the Palestinian Territories.

All the presented results in this section confirm the existence of the problem that has been expressed in the beginning of this study, and we were able to identify some of the reasons that lead to higher rates of unemployment among female graduates disproportionately with nongraduate females who were not educated beyond high school. This helps focus on the importance of working and add more efforts to overcome some particular obstacles faced by female graduates unlike male graduates.

Figure 17: Probability of individuals' (20-39 years old) transition to one of the six categories by gender and educational level

First level: individuals who finished 12 years of education or less

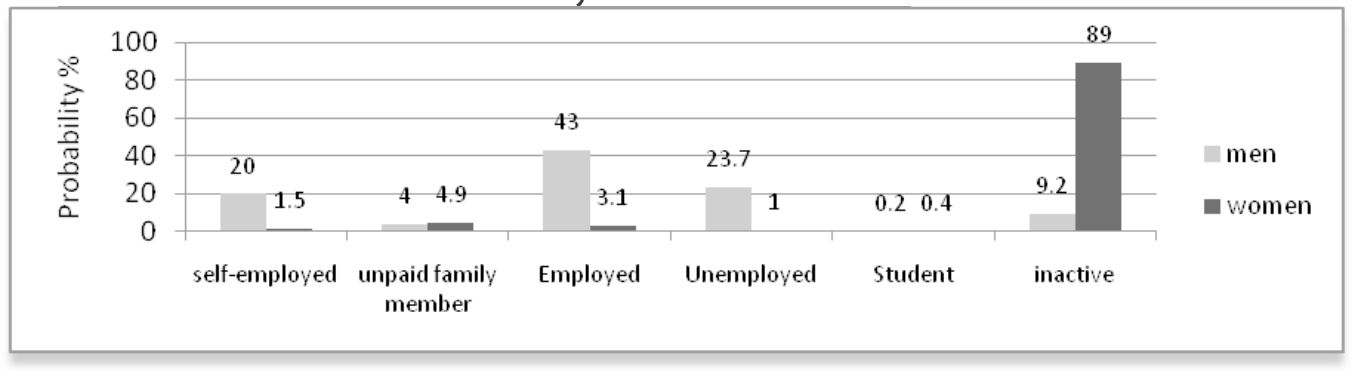

Second level: individuals with have diploma degree (13-15 years of education)

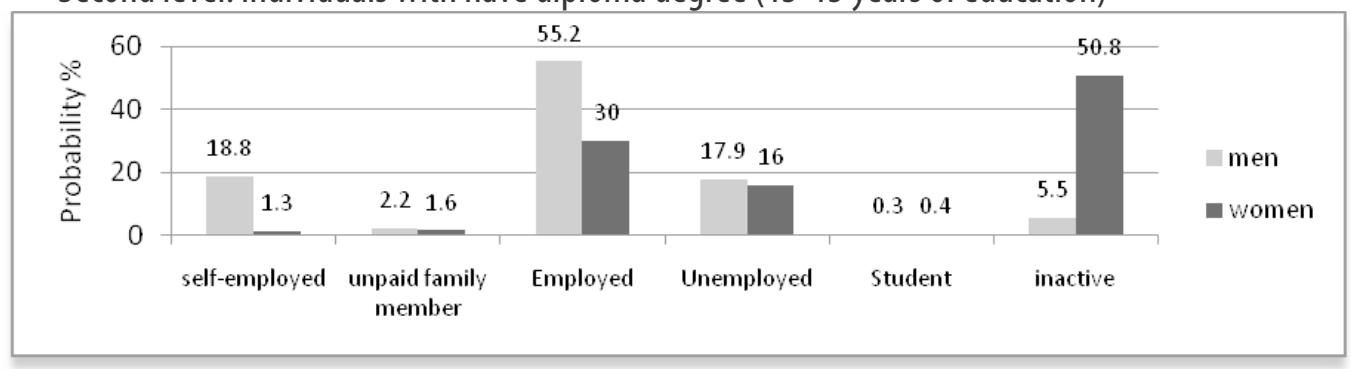


Third level: individuals with Bachelor degree and higher education (16 years and more)

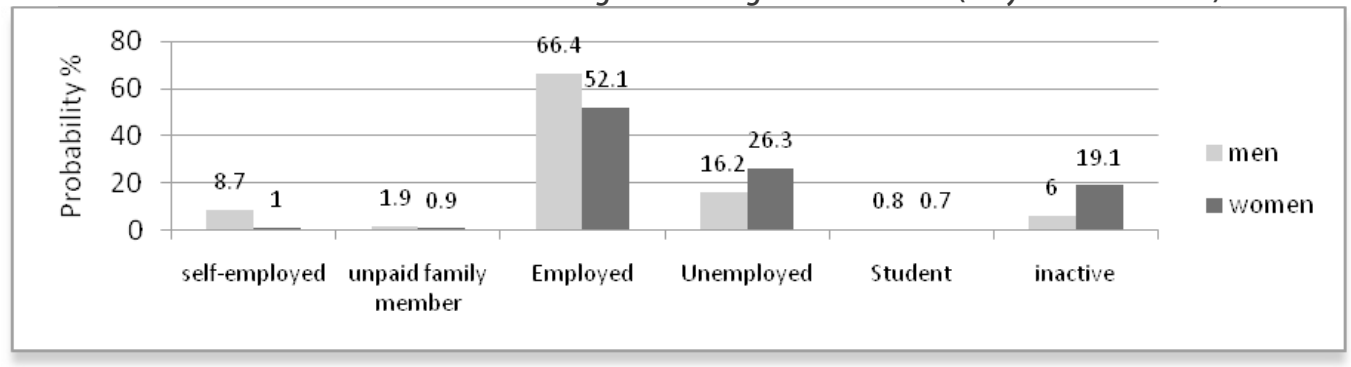

\section{Factors of graduates unemployment}

This part of the study, aims at identifying the most important factors that lead to unemployment of graduates (male and female)in the West Bank and the Gaza Strip regarding the following:

- The basic characteristics of the family

- Geographic location of the graduate (resident)

- Educational level and characteristics of the graduate

- Field of study

\subsection{Methodology}

To identify the determinants/factors of unemployment of graduates the probit regression equation was utilized:

$$
U=\beta+\alpha_{i} \mathrm{X}_{\mathrm{i}}+\varepsilon
$$

In this equation, the dependent variable is identified by the unemployment indicator. Each individual was classified as either unemployed, and takes the value I, or employed, and takes the value o.

The target unit was identified as youth aged $20^{-3} 3$ who were economically active and had finished their education, either as a graduate or having quit formal education. The explanatory variables $\boldsymbol{X}_{i}$ include the variables below that have been identified based on the results of the previous analysis. When choosing the set of indicators, we took into account the importance of the outputs that enable us to draw specific conclusions through the study of the main factors that cause the higher rate of unemployment among women compared to men, so these factors can be of the same type that may enable the decision makers to identify the policies in order to avoid the negative factors and to enhance the positive. 
The data of the quarterly survey of the Palestinian workforce for the period 2007-2008 has been utilized. It should be noted that the Palestinian Central Bureau of Statistics survey has been carried out periodically since I995 using sample rotation'. The number of observations that we dealt with are I4.I73, which is a reasonable sample to obtain estimations close to the reality.

\subsection{The Results}

At the beginning we divided the analysis of the results of the probit regression according to the groups of the factors used in the analysis (See Annexes I and 2). The first is concerning the characteristics of households in terms of who is the head of the family and the dependency ratio, i.e., number of dependents per economically active family member. It was noted that the gender of household head has an impact on the youth in the West Bank while it does not have an impact on the youth in the Gaza Strip. The results show that households headed by women raise the possibility of male unemployment in the West Bank, while it reduces the possibility of female unemployment. But it has a positive impact on young people in the Gaza Strip, although the degree of the statistical indicators is not significant, and this could return to the presence of particular care and interest to those families. Moreover, the dependency ratio shows a negative impact on young people. In the case of females, this can be interpreted as indicating that a high dependency ratio is a reason why women need to apply for jobs, and therefore it is not easy for them to exit the labor market even in the case of a prolonged job search. This suggests that women mostly work for economic reasons.

The geographical location of the place of residence of young people has an impact on the possibility of getting a job. This is especially true for women because of the restrictions imposed on them by the lack of acceptance of the idea of working away from the place of residence of their families, especially when the location of work requires them to stay overnight. Therefore, some geographical areas in the West bank have been identified, on the basis of their distance from the center, which provides the most employment in the public sector and international and non-governmental organizations (NGOs). Living in the northern parts

3 Each round of the Labor Force Survey covers all the 481 master sample areas. Basically, the areas remain fixed over time, but households in $50 \%$ of the EAs are replaced each round. The same household remains in the sample over 2 consecutive rounds, rests for the next two rounds and represented again in the sample for another and last two consecutive rounds before it is dropped from the sample. A 50\% overlap is then achieved between both consecutive rounds and between consecutive years (making the sample efficient for monitoring purposes). 
of the West Bank, except Nablus, significantly raises the probability of unemployment for women, with statistical significance, while reducing the probability of unemployment for males. Concerning the northern areas (far from the center), they can be considered a less fortunate place for graduates, because it has a high percentage of graduates with a high level of education seeking jobs, compared with other regions. More specifically, the unemployment rate is $54 \%$ in the north, $41 \%$ in the southern West Bank, and $19 \%$ in the middle of the West Bank. In addition, the results show that the refugee camps in the West Bank raise the possibility of unemployment among graduates regardless the gender. While the urban areas of the southern region raise the probability of male unemployment, they reduce female unemployment. The center of the West Bank reduces the probability of unemployment for both sexes. On the other hand, the countryside has a role in reducing male and female unemployment in the West Bank. Consequently, we can identify and map the weakest regions with the provision of offering opportunities for graduates which must be focused on by decision-makers.

Now, regarding the characteristics of graduates and the impact of these properties on getting a job, there are many findings that are worth highlighting. The model indicates that more years of education decreases the probability of unemployment among young men, while it increases the probability of unemployment among young women, which was confirmed by the transition probability matrix. Also, as the youth grow, their probability of obtaining employment increases, but for males it has greater positive impact. Moreover, marriage reduces the probability of unemployment for males in both the West Bank and for females in the Gaza Strip significantly. However, marriage raises the possibility of unemployment of females in the West Bank.

Finally, we discuss here the impact of the specializations and degrees. Through the results, we can map the best specializations for graduates compared with other careers. We start with young males in the West Bank and compare their bachelor's degree specializations. The results of all majors of bachelor's degree graduates are statistically significant, except the specializations of medicine, health, and human sciences. Specializations that increase the risk of unemployment are the social and behavioral sciences, natural sciences, business and administrative sciences, and engineering. Also, mathematics and computer science increase the risk, but in terms of low statistical indication. Figure is shows that the business and administration science specializations have the highest impact on raising the unemployment rate, while the educational and teacher training is the best way to reduce the likelihood of unemployment for males (see Figure iq). 
Figure 19: Possibility of unemployment of Bachelor graduates in west Bank by specialization-Males (for comparison, not to use the value)

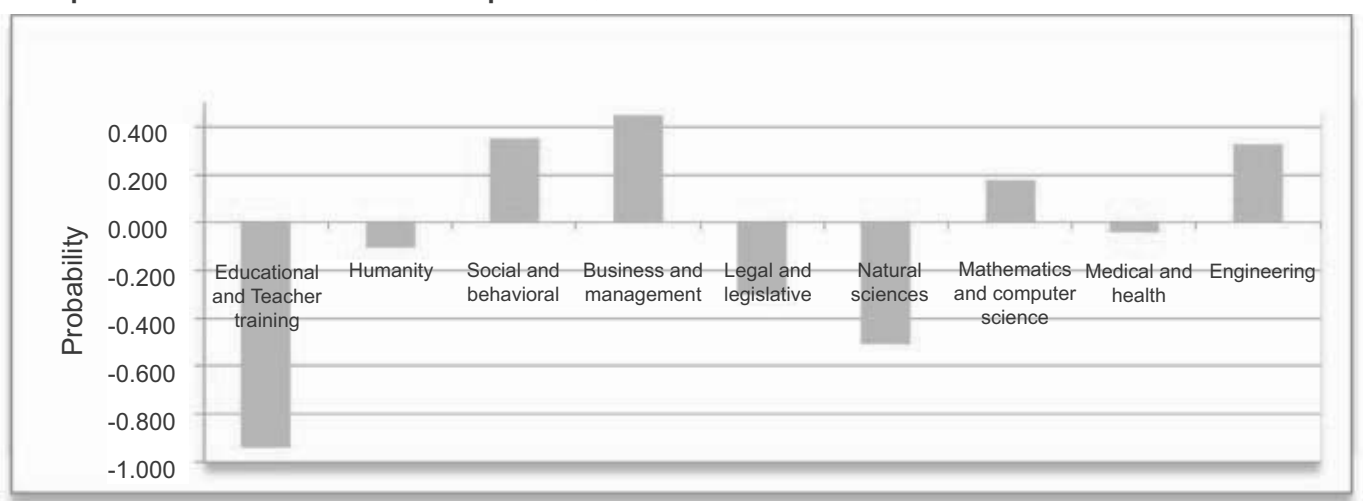

For female graduates with a bachelor's degree in the West Bank, all of the specializations raise the possibility of unemployment except for medicine and health sciences. The majors most likely result in unemployment are education, teacher training, and human sciences, followed by specializations in legal, legislative, and natural sciences (see Figure 20).

Figure 20: Possibility of unemployment of Bachelor graduates in west Bank by specialization-females (for comparison, not to use the value)

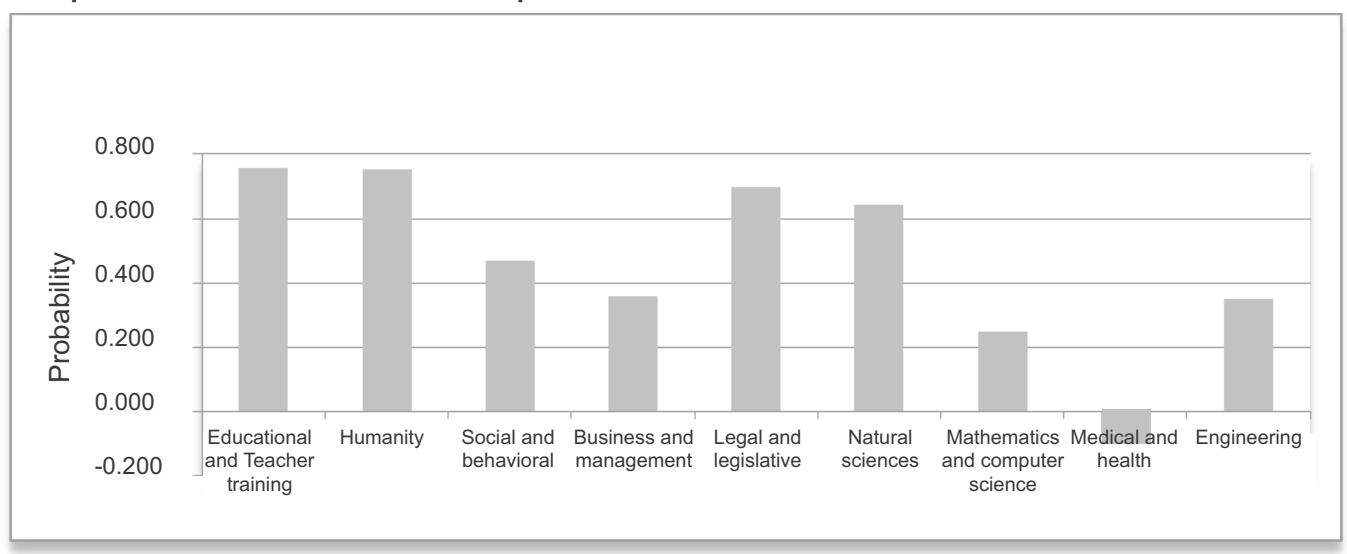

For the male BA holders in the Gaza Strip, the natural sciences specialization is the best in reducing the probability of unemployment. While the rest of the specializations raise the possibility of unemployment, but unevenly. The results show that engineering sciences have the most negative impact on employment of young males in the Gaza Strip, followed by mathematics and computer science, then followed by educational science and teacher training (see Figure 2I). 
Figure 21: Possibility of unemployment of Bachelor graduates in Gaza Strip by specialization-Males (for comparison, not to use the value)

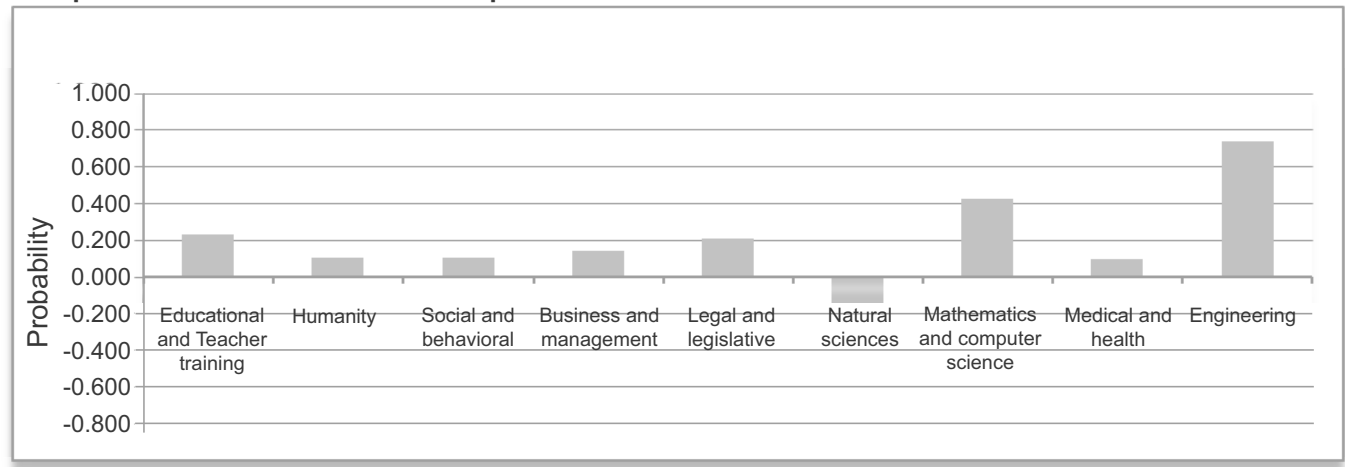

For the female bachelor's degree graduates in the Gaza Strip, health and medical education and teacher's training are the best majors to reduce the unemployment rates; while the rest of the specializations have a negative impact, but unevenly. Business and administration sciences, followed by social and engineering sciences have the most negative impact that raise the unemployment rate among female graduate in the Gaza Strip (see Figure 22).

Figure 22: Possibility of unemployment of Bachelor graduates in Gaza Strip by specialization-Females (for comparison, not to use the value)

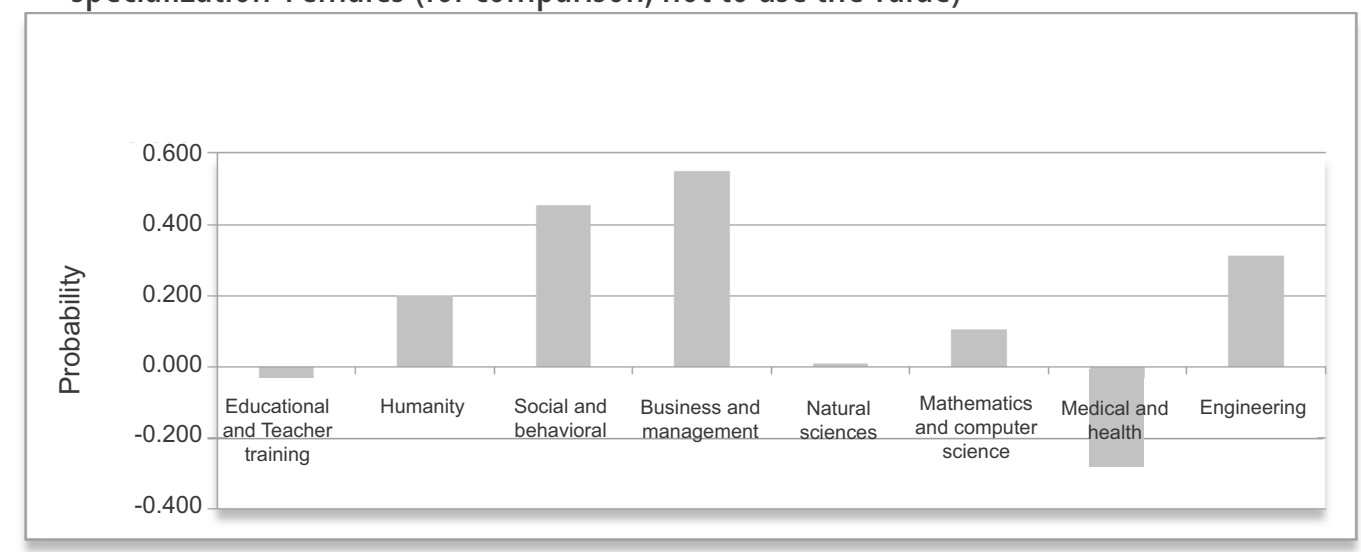

As for the two-year diploma, it has a negative effect for it may raise the probability of unemployment for both sexes in the Gaza Strip, while only for females in the West Bank. The diploma degree reduces the unemployment probability for males in the West Bank. This specified factor has high statistical significance. Where, it is now obvious that the demand for that class is low. Note that the participation rate among diploma graduate females is not more than half, and this may be an indication as to why the females holding a diploma quit the labor market, and consequently their low participation in the workforce. 


\section{Future Challenges}

Palestinian decision-makers face a serious challenge in providing employment opportunities for graduates and especially for women whose educational levels are rising rapidly, which of course increases their participation in the workforce. Figure 23 shows the witnessed acceleration of women's participation in the Palestinian Territories' workforce. This is caused mainly by their enrollment in higher education. According to the data available on the rate of growth in women's education and it's relation to their participation in the labor market during the period $1996^{-}$ 2008 , there was natural growth that affected the rising level of education among youth and their participation in the labor force. This is the case even and avoiding any complex scenarios related to the political situation, political solutions, and the Israeli actions.,. Excluding any efforts aimed at accelerating the participation of Palestinian women in the labor force, we note that there is a remarkable growth in women's participation due to high enrollment rates in higher education. Today's generation which is involving and participating in accelerating good standards in education will be the generation of tomorrow. Therefore, we can predict that the minimum participation of Palestinian women in the labor market will rise up to $44 \%$ in the year 2032 . However, with the current effort of the international, local, and governmental organizations to increase the participation of Palestinian women, regardless of their level of education, and its impact in raising participation, it is expected that the participation rate of women in 2032 will be close to that of men. So this is a challenge for decision-makers to provide a suitable environment for suitable employment to cope with the growing workforce, which its minimum expectations are as they appear in the first scenario (see Figure 23). 
Figure 23: the future expectations for the diploma graduates (community colleges) and higher and the percentage of women's (20-64 years old) participation in the Palestinian Territories until year 2032.

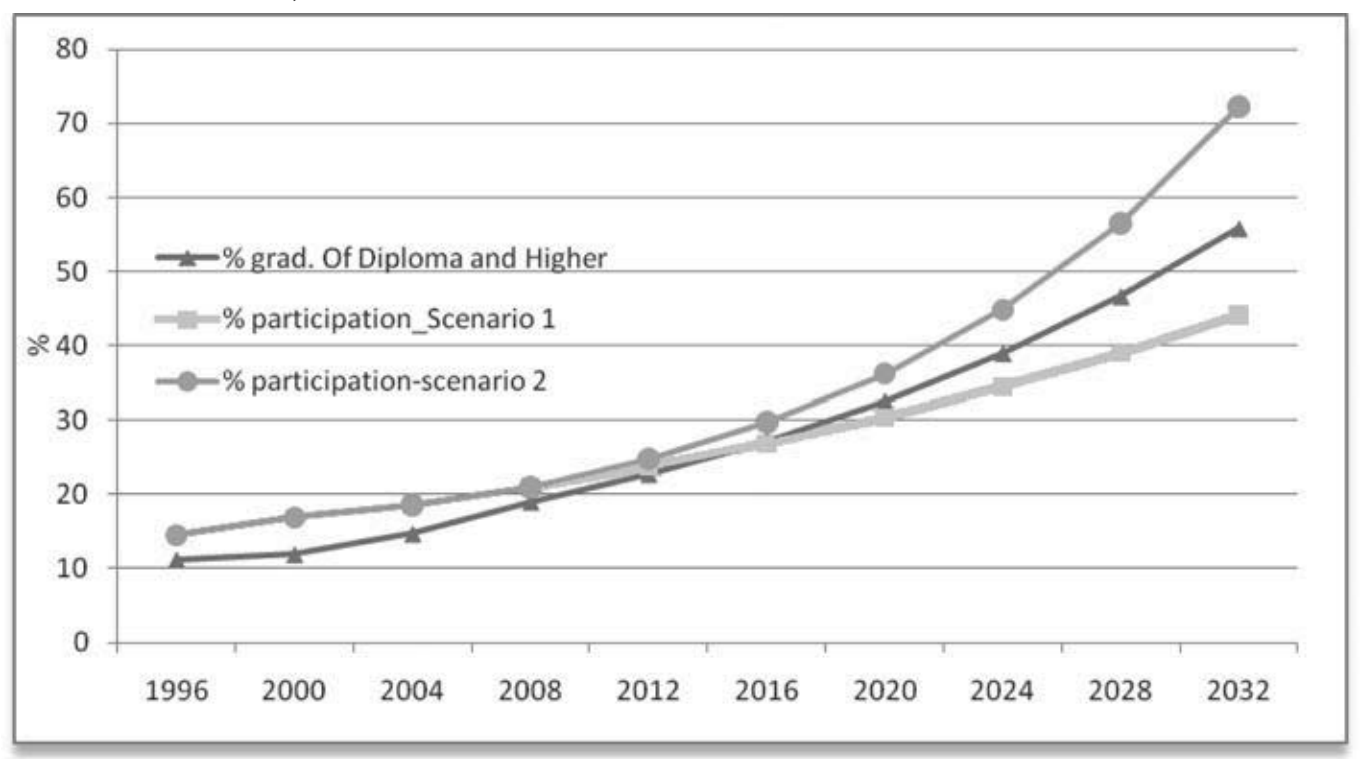

Source: Palestinian Central Bureau of Statistics, 2009. Labor Force survey 1996-2008. Ramallah-Palestine.

\section{Conclusions}

We can deduce from the above, that education has two dimensions for Palestinian women. The first dimension, which is positive, is through raising the level of education and knowledge and therefore has a positive impact on the development and accelerating economic growth and its development indicators, in addition to the positive effects of enhancing the role of women in economic participation and thus women's empowerment. The second is a negative dimension under the difficult economic conditions and political circumstances in the Palestinian Territories. For example, Palestinian women face the problem of getting the opportunity to work due to social constraints and the scarcity of jobs, particularly in the remote areas from the center of the West Bank and in the Gaza Strip. The problem of unemployment, especially for graduate females is the inability of families to take advantage of investments in education, which in the long-term can adversely affect family decisions and lead to avoiding investment in higher education, particularly higher than the diploma. It is noted that the general trend of women's participation in the labor force in recent years has declined below the level of growth associated with the growth of education at the population level. This indicates that women are reluctant to continue the search for work under difficult conditions, and this may therefore result in reluctance to invest in education in the future if the current situation persists. 
The reasons that hinder women from getting a chance to work can be the restrictions that prevent them from moving freely to access regions with more job opportunities i.e., the center of the West Bank. This is because of the political and military circumstances that hinder the movement of citizens causing families worry about the movement of their daughters between the cities and communities where there are many barriers (check points) of the military forces of the Israeli occupation. Also, the distinction can be seen when the employers prefer to recruit graduate females holding diploma for lower-level (lower class) jobs that could be performed with a lower level of education.

On the other hand, the specializations that the females head for are limited, which increases the probability of unemployment due to surplus in the availability (supply) of graduates of specific majors, especially in the presence of the low demand for them. Moreover, the conditions for women to accept jobs are more restricted than for men. This is accompanied by restricted choices for women in terms of fields to work in, when compared with men, who can create self-employment or work in certain professions that are acceptable to young males. Also, some jobs that women look for are not available in all geographical areas, nor are jobs matching women's particular needs for certain types of work. In other words the reason of high unemployment among female graduates is due to an increase in their petition for jobs under scarcity.

Finally, we come with the conclusion that the future challenges are bigger than the Palestinian local economy. Additionally, the acceleration of the increase in the demand for jobs in the Palestinian Territories and the decline in the investment and the creation of new job opportunities raises the level of challenges that await the Palestinian decision-maker. 


\section{References}

وإستطلاع الرأي، و . . r. عمل المرأة الفلسطينية: دراسة في انطباع الفلسطينيين

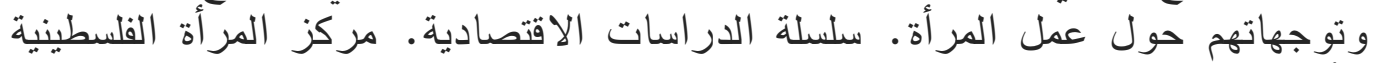
للأبحاث و التوثيق ، راتول عمل الله-فلسطين.

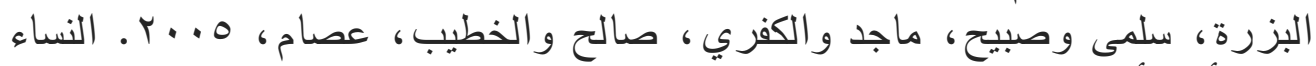

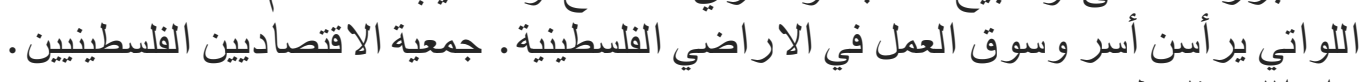

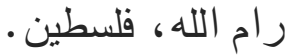

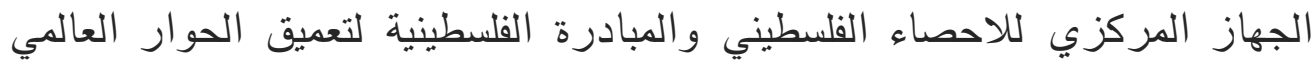

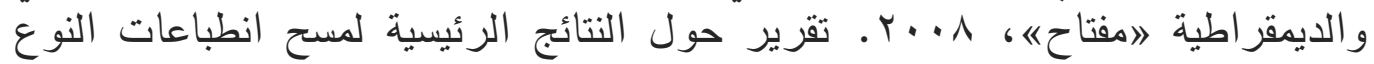

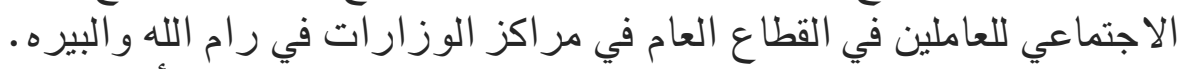

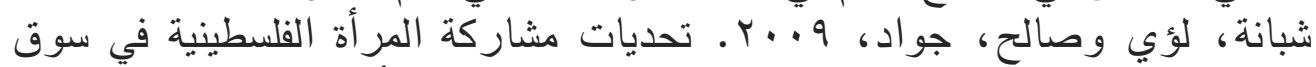

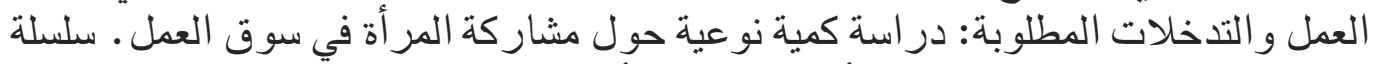

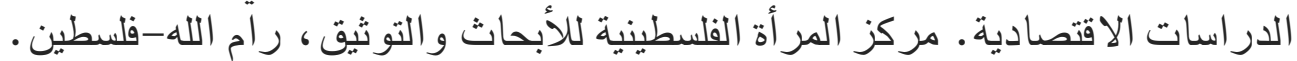

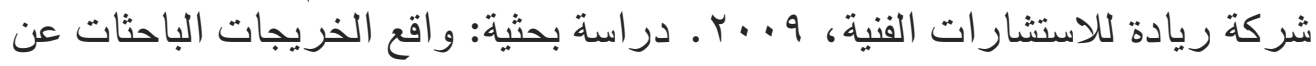

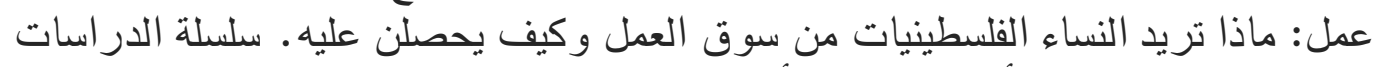

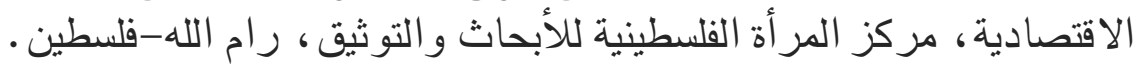

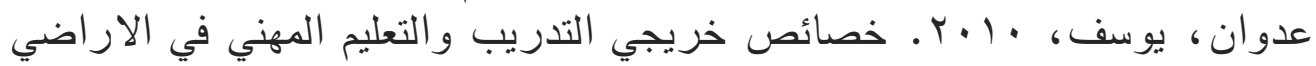

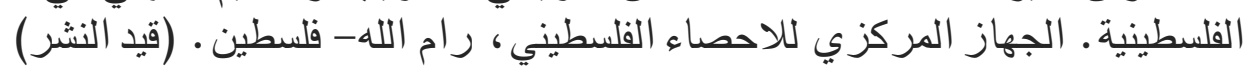

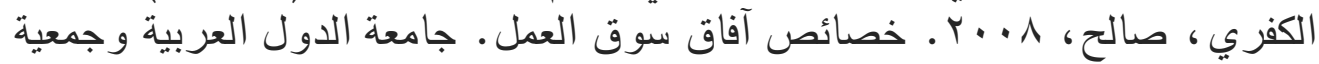

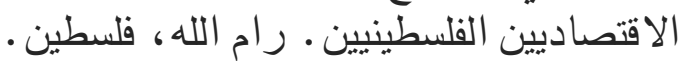

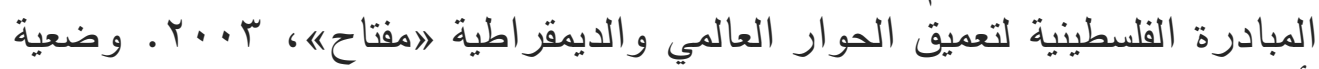

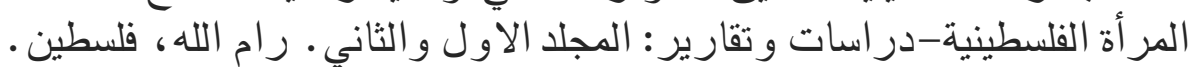

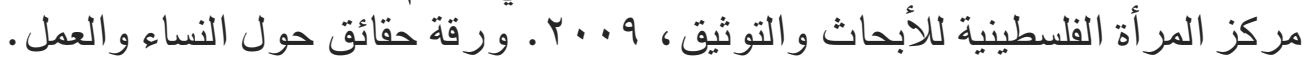

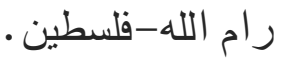


Albaek, K. and Hansen, H. 1999. "The Rise in Danish Unemployment: Reallocation or Mismatch?” fEL Classification: $\mathcal{F}_{41}$, $\mathcal{F} 6$ I.

AL-Kafri, S., 2002. "Impact of Israeli Measures on Palestinian Child Labor and Schooling," Working Paper No. 200215. Economic Research Forum (ERF). Egypt.

AL-Kafri, S., 2003. "The Palestinian Labor Force Dynamic Under the Israeli Occupation: An Impact Study and Lessons to be Learned for Restructuring the Labor Market", Working Paper Series. Economic Research Forum (ERF). Egypt.

Barceinas-Paredes, Fernado, Oliver-Alonso, Josep, Raymond, Jose Luis, Roig-Sabate, Weber, Bernhard, 200I. "Unemployment and returns to education in Europe", $\mathcal{F E L}$ classification: $I_{2}, \mathcal{F}_{2}$.

Bulmer, E., 200I. "The Impact of Future Labor Policy Options on the Palestinian Labor Market," Discussion Paper, World Bank.

Daoud, Y., 1999. "Gender Gap in Returns to Education in Palestine," Economics of Education Review, vol. 24, No. 6: 633-649.

Daoud, Y., 1999. "The Determinants of Labor Force Participation Rate for Women in the WB and GS". The Forum for Social and Economic Policy Research in Palestine. Ramallah,Palestine.

Hilal. J. \& AL-Kafri, S. \& Kuttab, E., 2008. "Unprotected Employment in the West Bank and Gaza Strip- A Gender Equality and Workers' Rights Perspective.” International Labour Organization, Beirut.

Kettunen, J. 1997. "Education and Unemployment Duration." Economics of Education Review, Vol. I6, No. 2: 163-170.

Lauer, Ch., 2005. "Education and Labour Markets Outcomes, A French-German Comparison.” ZEW Economic Studies.

Mahlwele, C. 2009. "Factors Associated with Women Unemployment in South Africa”. International Statistical Institution (ISI).

Palestinian Central Bureau of Statistics, 2006. "Graduates Conditions in Labor Market Survey 2006." Ramallah, Palestine.

Palestinian Central Bureau of Statistics, 2009. "Labor Force Survey Database 1996-2008." Ramallah, Palestine.

Thompson, J. and Palmer, T. and Moreno, S. 2009. "Bayesian Analysis in Stata using WinBUGS.” University of Leicester. UK.

Ryan, P. 20or. "The School-to-Work Transition: A Cross-National Perspective", Journal of Economic Literature, Vol. 39, No. I (Mar., 200I), pp. $34^{-9} 92$. 
Voicu, A., 2002. "Employment Dynamics in the Romanian Labor Market: A Markov Chain Monte Carlo Approach," Discussion Paper No. 438. Institute for the Study of Labor (IZA), Bonn-Germany.

Welton, N. and Ades, A.E. 2005. "Estimation of Markov Chain Transition Probabilities and Rates from Fully and Partially Observed Data: Uncertainty Propagation Evidence Synthesis, and Model Calibration." Medical Decision Making. http://mdm.sagepub.com 


\section{Probit Regression Model}

\section{Annex 1: For persons 20-34 years old who are not attend- ing school: West Bank 2007-2008 (Quarterly Base)}

\begin{tabular}{|c|c|c|c|c|}
\hline $\begin{array}{l}\text { Dependent } \\
\text { Variable=Unemployment } \\
\text { (1-Unemplyment }\end{array}$ & \multicolumn{2}{|c|}{ Males } & \multicolumn{2}{|c|}{ Females } \\
\hline Explanatory Variables & $\alpha$ & $P>z$ & $\alpha$ & $P>z$ \\
\hline $\begin{array}{l}\text { Head of household } \\
(1=\text { Female, } 0=\text { Male) }\end{array}$ & 0.072 & 0.376 & -0.184 & 0.149 \\
\hline $\begin{array}{l}\text { Dependency Ratio } \\
\text { (Household size divided by } \\
\text { active members) }\end{array}$ & 0.041 & 0.004 & 0.064 & 0.004 \\
\hline $\begin{array}{l}\text { Marital Status ( } 1=\text { Married, } \\
0=\text { Other) }\end{array}$ & -0.166 & 0.001 & 0.049 & 0.551 \\
\hline Age & -0.027 & 0.000 & -0.092 & 0.000 \\
\hline Years of Schooling & -0.031 & 0.000 & 0.050 & 0.006 \\
\hline $\begin{array}{l}\text { Locality type } 1 \text { ( } 1=\text { Camps in } \\
\text { West Bank, } 0=\text { other) }\end{array}$ & 0.101 & 0.315 & 0.156 & 0.344 \\
\hline $\begin{array}{l}\text { Locality type } 2 \text { ( } 1=\text { Urban in } \\
\text { South West Bank, } 0=\text { other) }\end{array}$ & 0.173 & 0.017 & -0.026 & 0.850 \\
\hline $\begin{array}{l}\text { Locality type } 3 \text { ( } 1=\text { Mid West } \\
\text { Bank, } 0=\text { other) }\end{array}$ & -0.443 & 0.000 & -0.511 & 0.000 \\
\hline $\begin{array}{l}\text { Locality type } 4 \text { ( } 1=\text { North } \\
\text { West Bank excluding Nablus, } \\
0=\text { other) }\end{array}$ & -0.087 & 0.078 & 0.165 & 0.070 \\
\hline $\begin{array}{l}\text { Locality type } 5 \text { ( } 1=\text { Rural, } \\
0=\text { other) }\end{array}$ & 0.304 & 0.000 & 0.109 & 0.231 \\
\hline $\begin{array}{l}1=\mathrm{BA} . \text { in Educational } \\
\text { Sciences and teachers } \\
\text { preparation, } 0=\text { other }\end{array}$ & -0.943 & 0.032 & 0.755 & 0.000 \\
\hline $\begin{array}{l}1=B A . \text { in Humanities, } \\
0=\text { other }\end{array}$ & -0.104 & 0.598 & 0.753 & 0.000 \\
\hline
\end{tabular}




\begin{tabular}{|c|c|c|c|c|}
\hline $\begin{array}{l}1=\text { BA. in Social and } \\
\text { Behavioral Sciences, } \\
0=\text { other }\end{array}$ & 0.348 & 0.011 & 0.469 & 0.008 \\
\hline $\begin{array}{l}1=\mathrm{BA} . \text { In Commercial and } \\
\text { Administrative Sciences, } \\
0=\text { other }\end{array}$ & 0.449 & 0.000 & 0.358 & 0.036 \\
\hline $\begin{array}{l}1=\text { BA. in Legal, and } \\
\text { Legislative Sciences, } \\
0=\text { other }\end{array}$ & -0.301 & 0.241 & 0.696 & 0.151 \\
\hline $\begin{array}{l}1=\text { BA. In Natural Sciences, } \\
0=\text { other }\end{array}$ & -0.508 & 0.097 & 0.642 & 0.003 \\
\hline $\begin{array}{l}\text { 1=BA. In Mathematics and } \\
\text { Computer Science, } 0=\text { other }\end{array}$ & 0.179 & 0.304 & 0.249 & 0.174 \\
\hline $\begin{array}{l}1=\text { BA. In Medical and Health } \\
\text { Sciences, } 0=\text { other }\end{array}$ & -0.042 & 0.824 & -0.113 & 0.699 \\
\hline $\begin{array}{l}1=B A . \text { In Engineering } \\
\text { Science, } 0=\text { other }\end{array}$ & 0.329 & 0.021 & 0.349 & 0.124 \\
\hline $1=$ Diploma, $0=$ other & -0.120 & 0.180 & 0.475 & 0.000 \\
\hline$\beta$ & 0.237 & 0.197 & 0.720 & 0.033 \\
\hline Number of observation & \multicolumn{2}{|c|}{7780} & \multicolumn{2}{|c|}{2292} \\
\hline Wald chi2(16) & \multicolumn{2}{|c|}{336.1} & \multicolumn{2}{|c|}{291.47} \\
\hline Prob > chi2 & \multicolumn{2}{|c|}{0} & \multicolumn{2}{|c|}{0} \\
\hline Pseudo R2 & \multicolumn{2}{|c|}{0.0555} & \multicolumn{2}{|c|}{0.1812} \\
\hline Log pseudo likelihood & \multicolumn{2}{|c|}{-3853.06} & \multicolumn{2}{|c|}{-1102.25} \\
\hline
\end{tabular}




\section{Annex 2: For persons 20-34 years old who are not attend- ing school: Gaza Strip 2007-2008 (Quarterly Base)}

\begin{tabular}{|c|c|c|c|c|}
\hline $\begin{array}{l}\text { Dependent } \\
\text { Variable=Unemployment } \\
\text { (1-Unemplvment }\end{array}$ & \multicolumn{2}{|c|}{ Males } & \multicolumn{2}{|c|}{ Females } \\
\hline Explanatory Variables & $\alpha$ & $P>z$ & $\alpha$ & $P>z$ \\
\hline $\begin{array}{l}\text { Head of household } \\
(1=\text { Female, } 0=\text { Male) }\end{array}$ & -0.038 & 0.718 & -0.086 & 0.601 \\
\hline $\begin{array}{l}\text { Dependency Ratio } \\
\text { (Household size divided } \\
\text { by active members) }\end{array}$ & 0.034 & 0.043 & 0.008 & 0.813 \\
\hline $\begin{array}{l}\text { Marital Status ( } 1=\text { Married, } \\
0=\text { Other) }\end{array}$ & -0.460 & 0.000 & -0.065 & 0.582 \\
\hline Age & -0.031 & 0.000 & -0.081 & 0.000 \\
\hline Years of Schooling & -0.071 & 0.000 & 0.095 & 0.003 \\
\hline $\begin{array}{l}\text { Locality type ( } 1=\text { Rural, } \\
0=\text { other })\end{array}$ & 0.355 & 0.000 & -0.237 & 0.148 \\
\hline $\begin{array}{l}1=\mathrm{BA} \text { in Educational } \\
\text { Sciences and Teaches } \\
\text { preparation, } 0=\text { other }\end{array}$ & 0.234 & 0.382 & -0.059 & 0.791 \\
\hline $\begin{array}{l}1=\text { BA. In Humanities, } \\
0=\text { other }\end{array}$ & 0.105 & 0.634 & 0.200 & 0.302 \\
\hline $\begin{array}{l}1=\text { BA. In Social and } \\
\text { Behavioral Sciences, } \\
0=\text { other }\end{array}$ & 0.102 & 0.505 & 0.455 & 0.029 \\
\hline $\begin{array}{l}1=\text { BA. In Commercial and } \\
\text { Administrative Sciences, } \\
0=\text { other }\end{array}$ & 0.139 & 0.368 & 0.551 & 0.051 \\
\hline $\begin{array}{l}1=\mathrm{BA} . \text { In Legal, and } \\
\text { Legislative Sciences, } \\
0=\text { other }\end{array}$ & 0.208 & 0.475 & .. & .. \\
\hline
\end{tabular}




\begin{tabular}{|c|c|c|c|c|}
\hline $\begin{array}{l}1=\text { BA. In Natural Sciences, } \\
0=\text { other }\end{array}$ & -0.577 & 0.210 & 0.007 & 0.980 \\
\hline $\begin{array}{l}1=\text { BA. In Mathematics } \\
\text { and Computer Science, } \\
0=\text { other }\end{array}$ & 0.430 & 0.051 & 0.103 & 0.661 \\
\hline $\begin{array}{l}1=\text { BA. In Medical and } \\
\text { Health Sciences, } 0=\text { other }\end{array}$ & 0.096 & 0.658 & -0.282 & 0.264 \\
\hline $\begin{array}{l}1=B A . \text { In Engineering } \\
\text { Science, } 0=\text { other }\end{array}$ & 0.737 & 0.001 & 0.312 & 0.511 \\
\hline $1=$ Diploma, $0=$ other & 0.501 & 0.000 & 0.679 & 0.000 \\
\hline$\beta$ & 1.597 & 0.000 & 0.748 & 0.244 \\
\hline Number of observations & \multicolumn{2}{|c|}{3310} & \multicolumn{2}{|c|}{791} \\
\hline Wald chi2(16) & \multicolumn{2}{|c|}{275.32} & \multicolumn{2}{|c|}{86.11} \\
\hline Prob > chi2 & \multicolumn{2}{|c|}{0} & \multicolumn{2}{|c|}{0} \\
\hline Pseudo R2 & \multicolumn{2}{|c|}{0.0751} & \multicolumn{2}{|c|}{0.1105} \\
\hline Log pseudo likelihood & \multicolumn{2}{|c|}{-2102.19} & \multicolumn{2}{|c|}{-477.93} \\
\hline
\end{tabular}



